\title{
EL MOLÓN (CAMPORROBLES, VALENCIA). UN POBLADO DE PRIMERA ÉPOCA ISLÁMICA
}

\author{
El MOLÓN (CAMPORROBLES, VALENCIA). \\ AN EARLY ISLAMIC SETTLEMENT
}

\author{
A. J. LORRIO ALVARADO \\ $M^{\mathrm{a}}$ D. SÁNCHEZ DE PRADO \\ Universidad de Alicante
}

\section{INTRODUCCIÓN}

En las proximidades de la localidad de Camporrobles (Valencia), en el límite provincial con Cuenca, se localiza una gran muela cretácica conocida como El Molón, de 1.124 m s.n.m ${ }^{1}$ (Fig. 1,1-2). Presenta forma alargada y se encuentra estructurada en varias plataformas, ofreciendo una estratégica localización geográfica, en la zona de transición de la Meseta, las Serranías Ibéricas y el litoral mediterráneo, al ejercer un claro control del cruce de las vías que descendían de las Serranías de Cuenca y Albarracín hacia las zonas levantinas por el corredor de Utiel y Requena; por otra parte, a los pies del cerro se localizaba una extensa área lagunar, desecada en los años 60 del siglo XX (Fig. 1,3). Serán, pues, su valor estratégico, su inexpugnabilidad natural y sus inmejorables condiciones topográficas, con una amplia cumbre amesetada de cerca de 1 ha, lo que favorecería una ocupación continua que se desarrolla desde el siglo VII a.C. hasta mediados del I a.C., abandonándose a partir de esos momentos, cuando tras el cambio en el patrón de asentamiento impuesto por la conquista romana se constata una dispersión del poblamiento en pequeñas explotaciones agrarias que se van a situar en tierras mas favorables para el cultivo, de las que se conocen algunos ejemplos en el entorno de Camporrobles, destacando los restos de una posible villa en el llano, al noroeste de la actual población, junto a la antigua laguna².

\footnotetext{
1. Sus coordenadas UTM son 30SXJ376921. Mapa topográfico del Servicio Geográfico del Ejército, Hoja 665 de Mira, ed. 1996 (1:50.000).

2. El yacimiento, conocido como «La Balsa», se descubrió en 1978 tras unas remociones del terreno al iniciarse las obras del área polideportiva del municipio, realizándose una serie de sondeos dirigidos por M. Gil-Mascarell, que habrían de proporcionar un abundante material tardorromano, en general producciones africanas, mezclado con cerámicas medievales o incluso modernas, sin que se hubiera documentado estructura alguna (Fletcher, 1979, 74), aunque durante las
}

\section{EL FINAL DEL MUNDO ANTIGUO: LOS «SI- GLOS OSCUROS»}

Como apuntaba hace algunos años A. Bazzana (1992, 37 ss.), al iniciar su trabajo sobre el poblamiento medieval en el Levante peninsular, existe un vacío documental sobre las claves que marcaron la transición entre la Antigüedad Tardía y los primeros siglos medievales, tanto por lo que se refiere a las fuentes literarias, como a las arqueológicas, que parecen mostrar un país debilitado y prácticamente despoblado, señal de un declive generalizado, acentuado en el área valenciana, donde importantes ciudades romanas, como Saguntum o Valentia, sufrieron una progresiva transformación urbana a partir del siglo III, más marcada entre los siglos IV-V d.C. (Ribera, 2003, 235 ss.), una tendencia similar a la registrada en otros núcleos urbanos del Sureste peninsular ${ }^{3}$. Por otra parte, es interesante resaltar el escaso impacto que supuso, en esta zona, el mundo visigodo, que se plasmaría más en el plano político que en el cultural, constatándose una serie de hallazgos aislados que más bien reflejan una realidad anclada en la tradición tardorromana, marcando una continuidad, más aparente que real, que no debe disfrazar lo que era ya imparable: el declive generalizado de estas regiones durante el inicio de la Alta Edad Media (Bazzana, 1992, 38 ss.). Los estudios llevados a cabo en las tierras valencianas apuntan cómo el final del Reino visigodo, sobre todo a partir de la segunda mitad del siglo VII, estuvo marcado por una serie de calamidades relatadas por las crónicas de la época, a

obras se recuperaron numerosos sillares, algunos almohadillados, y restos de ladrillos romboidales y circulares, evidencias de la existencia de unas termas asociadas. La valoración de los conjuntos monetales y materiales hallados en la zona permiten encuadrar este asentamiento entre los siglos II-IV o inicios del V d.C. (de la Pinta et alii, 1987-88, 310 s.).

3. En relación a esta problemática, véase el trabajo de Gutiérrez (1996, 222 ss.) sobre las diversas ciudades que participaron en el Pacto de Teodomiro. 


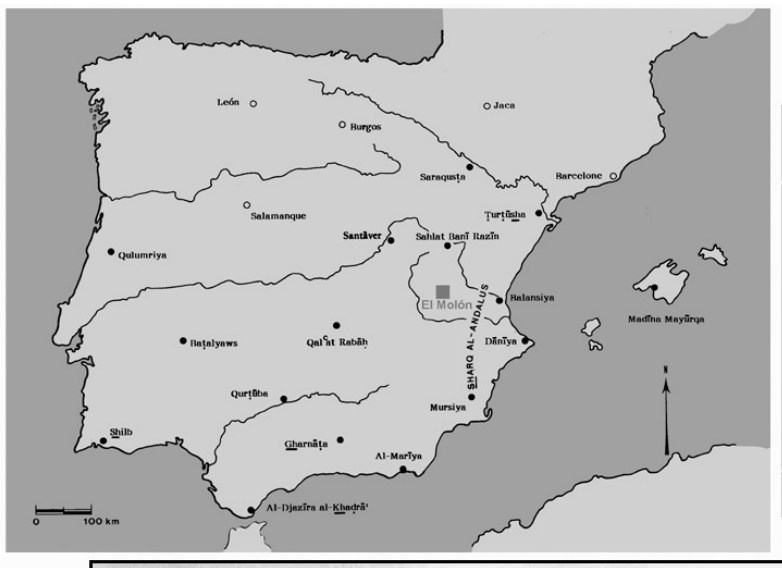

1
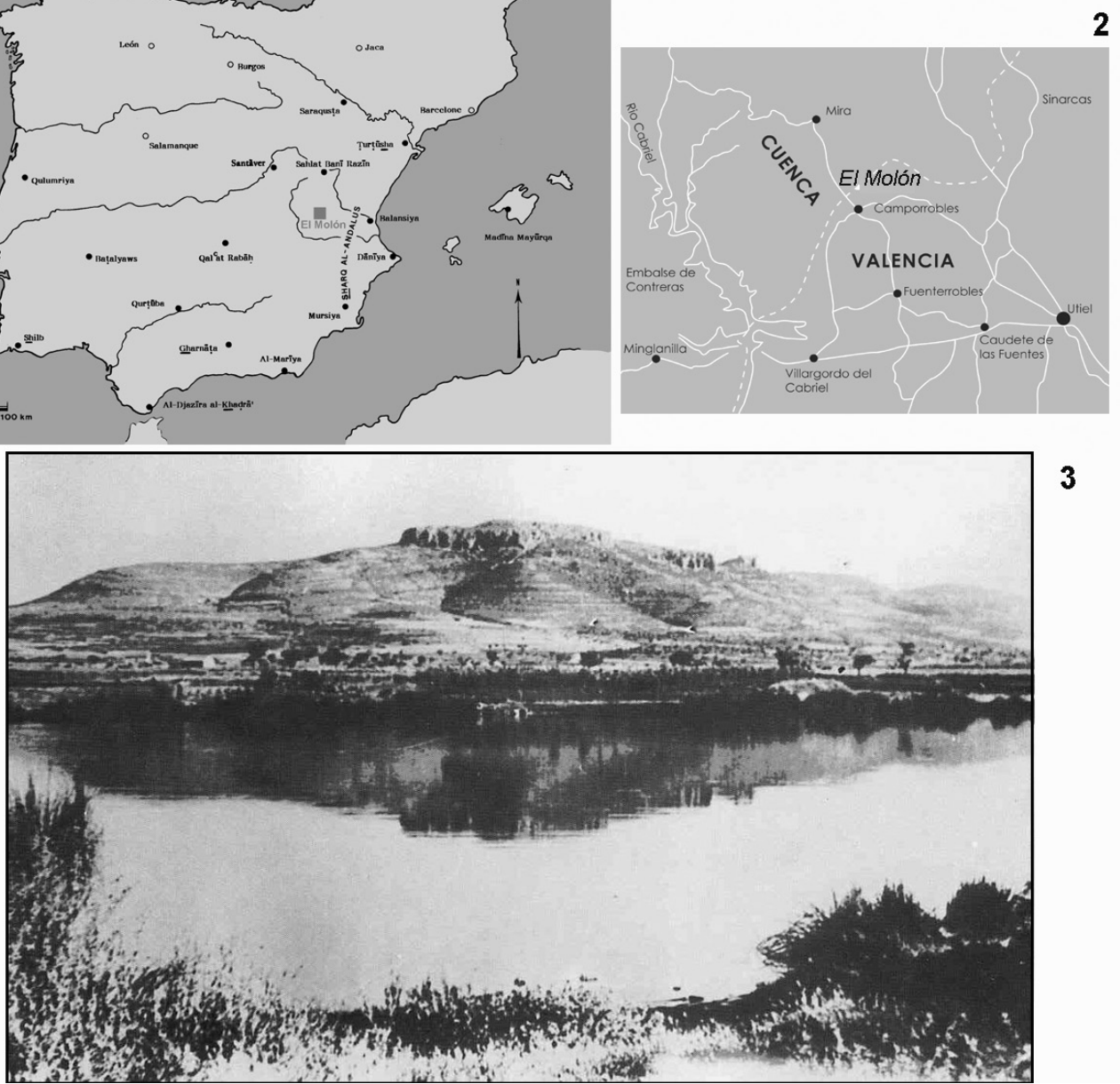

Figura 1: Mapa de la Península Ibérica en época emiral, con la localización de El Molón (1) y su situación según la división administrativa actual (2). Vista de El Molón desde el Sur con la laguna «La Balsa», en primer término (3) (1, según Bazzana, 1992; 3, foto R. Gómez).

lo que se suma la gran inestabilidad política existente que conllevaría una ruptura social; en definitiva una serie de problemas que acelerarían su final y la posterior conquista musulmana (Ribera y Roselló, 2003, 103 ss.). Sin embargo, esta llegada no supondría, en un principio, cambio alguno, dada la existencia del Pacto de Teodomiro (Gutiérrez, 1996), un tratado gracias al cual una amplia zona del Sureste peninsular mantuvo durante un tiempo su estilo de vida, siendo a partir de mediados del siglo VIII cuando los contingentes árabes se instalarían en el sur del territorio valenciano, mientras que los beréberes lo harían en las tierras del centro y norte, iniciándose un lento pero progresivo proceso de islamización, del que arqueológicamente poco se sabe (Ribera, 2003, 242).

En líneas generales y como se ha ido apuntando, la descomposición de la antigua ciudad romana se irá gestando desde la crisis del siglo III, poniéndose de manifiesto un progresivo declive urbano, para unos, o una continua evolución para adaptarse a nuevos tiempos, para otros, cuya culminación se ha llevado tradicionalmente al siglo VII d.C. (Gutiérrez, 1993, 14), y que aparece caracterizado por una serie de signos que evidencian la lenta pero progresiva transformación de la antigua urbe, como la reocupación de los espacios públicos, destinados a otras finalidades como viviendas particulares, vertederos o, incluso, como espacios funerarios; la proliferación de espacios de cultivo en zonas antes urbanizadas, o el expolio y posterior reutilización de los materiales constructivos, muestra, en realidad, de la continuidad en la actividad edilicia. Ciertamente estas transformaciones se relacionan estrechamente con una fuerte crisis social, que muestra un desequilibrio cada vez mayor que va a conllevar la lenta pero imparable dispersión o huida de aquellos grupos menos favorecidos que buscarán, en el medio rural, nuevos emplazamientos; una tendencia que se va a generalizar a partir del siglo V d.C. (Gutiérrez, 1996, 275), y que va a dar lugar a un nuevo fenómeno como será la reocupación de las alturas (Bazzana, 1992, 41 s.), bien documentado arqueológicamente en el área levantina donde encontramos, a partir de esos momentos, numerosos poblados ubicados en lugares de difícil acceso y protegidos, en muchos casos, por una topografía muy abrupta, situándose en la cumbre de elevaciones que ejercen un claro dominio sobre el paisaje circundante, y alejados de la costa. 
Si analizamos, por ejemplo, la zona de Castellón ${ }^{4}$ (Bazzana, 1986b, 147 s.), comprobamos cómo arqueológicamente se han registrado en La Plana diversos asentamientos romanos que llegan a los siglos IV-V d.C., despoblándose a partir de entonces, al tiempo que se reocupan otros más antiguos, de la Edad del Hierro, como algunos localizados en las estribaciones del Bajo Maestrazgo. Un ejemplo de ello lo constituyen los yacimientos castellonenses de El Castellar de Chilches o La Torre del Mal Paso (Castellnovo), que han proporcionado abundante material ibérico, tardorromano y medieval. Éstos, de carácter indígena, se han encuadrado entre los siglos V-VII d.C., siendo considerados como «sitios de transición» (Bazzana, 1992, 275), pues marcan los inicios de esta etapa caracterizada por la reocupación sistemática de las alturas. Por su parte, en la provincia de Alicante, hay que citar el asentamiento emplazado en la cima de El Pic Negre de Cocentaina (Torró, 1998, 394), un asentamiento ibérico que se reocupa, al parecer, hacia el siglo V y durante primera época islámica, abandonándose, según Torrró $(1998,394)$ hacia el 930, coincidiendo con la sumisión de la zona a los Omeyas. Un momento en el que, igualmente, se despueblan otros asentamientos como el Castellar de Meca (Ayora, Valencia), un importante oppidum prerromano que parece presentar una situación similar y que se abandona durante la primera mitad del siglo IX d.C. (Bazzana, 1992, 409), así como algunos poblados fortificados de la provincia de Castellón, pudiendo destacar los sitios de Monte Mollet (Villafamés) y Monte Marinet (Chodos), dos de los más interesantes yacimientos altomedievales que, aunque de cronología incierta ${ }^{5}$, parecen ofrecer una corta perduración, y cuyo estudio va llenando, paulatinamente, ese vacío que parece caracterizar el espacio temporal que discurre entre los siglos VII y X d.C. (Bazzana, 1986b, 148 ss.; Bazzana, 1992, 274).

Es interesante recalcar cómo los investigadores se enfrentan a dos importantes problemas al estudiar estos yacimientos, que ofrecen, en general, tanto una falta de precisión cronológica, como cierta dificultad a la hora de relacionarlos con los nuevos grupos poblacionales

4. El poblamiento en altura en el territorio de la Cora de Tudmîr ha sido analizado pormenorizadamente por S. Gutiérrez (1996, 275 ss.), donde se comprueba la generalización de este fenómeno desde el siglo $\mathrm{V}$ d.C. por las gentes indígenas, y que se acentuaría por la conquista islámica.

5. Como señala Bazzana $(1992,274)$, al referirse a tal imprecisión cronológica, tanto Mollet como Marinet, no han proporcionado cerámica ibérica, ni romana bajoimperial, y su atribución a época visigoda parece improbable. La cerámica registrada remite casi exclusivamente al tipo olla, con una completa ausencia, en el caso de Mollet, de producciones califales, lo que le llevó a situarlos, tras un primer análisis, entre los siglos V y X d.C., una amplia horquilla cronológica todavía a falta de precisar para cada sitio, que, según este mismo autor, debe situarse más bien cerca del siglo IX, añadiendo «quizás a principios de la conquista árabe», que del VII (Bazzana, 1986b, 160). de indígenas, árabes y beréberes, que habitaron estas tierras desde el siglo VIII (Bazzana y Guichard, 1978, 498; Bazzana, 1986b, 160). Sin embargo los diferentes estudios llevados a cabo tanto en el Sureste como en estas tierras del interior levantino ${ }^{6}$, van permitiendo avanzar algo en este sentido. De tal modo, ya Bazzana $(1992,275)$ señalaría el carácter indígena de algunos de estos sitios de transición, como El Castellar de Chilches, al que relaciona con gentes que se establecerían en estas áreas hacia el siglo V d.C., a veces sobre lugares ocupados durante la Protohistoria, pues estos emplazamientos les van a permitir una economía agropecuaria de autosuficiencia, además de proporcionarles cierta inexpugnabilidad, ya natural, ya por el reaprovechamiento de los elementos defensivos anteriores, dejando entrever lo temprano de este fenómeno de ocupación de las alturas. Por el contrario y a diferencia de aquél, al tratar el asentamiento de Monte Mollet, con una mayor complejidad al ofrecer estructuras socialmente jerarquizadas, el autor plantea la posibilidad de estar ante un hábitat dirigido al control de un territorio nuevo y quizá despoblado, que habría que relacionar en este caso, no con una población local que busca el refugio de las alturas, sino con la sociedad guerrera conquistadora (Bazzana, 1992, 278). En definitiva, sirvan estos breves apuntes para mostrarnos parte de lo que sería el complejo panorama existente anterior al siglo X d.C., que dará paso, según Bazzana $(1992,42)$, a una fase durante la que el espacio rural aparecerá organizado, fundamentalmente, en hiṣn ${ }^{7}$ y qarya, lo que habría de constituir la base de la organización social de época islámica.

\section{EL MOLÓN, UN HIȘN DE PRIMERA ÉPOCA ISLÁMICA}

Si en los apartados anteriores nos hemos acercado a algunos de los ejemplos más señalados para analizar el poblamiento en el interior de las tierras valencianas, las excavaciones llevadas a cabo en El Molón nos permiten avanzar un punto más en la interpretación y el conocimiento de una etapa caracterizada por su propia complejidad.

6. Son fundamentales los trabajos ya señalados en notas anteriores de S. Gutiérrez (1996) y A. Bazzana (1992), que recopilan los resultados obtenidos tras años de investigación en estas dos zonas levantinas.

7. En realidad, como se ha ido exponiendo, el fenómeno de «encastillamiento», o la creación de refugios en altura, es claramente anterior, siendo un tema ampliamente tratado por $\mathrm{M}$. Acién (1990, Id. 2002), quien pone de relieve la ambigüedad del término hiṣn a la vez que señala los diversos tipos de núcleos fortificados que encontramos en las fuentes. También destaca el trabajo de Bazzana et alii (1988) sobre los hușūn en el Sureste peninsular, donde se trata exhaustivamente la terminología, así como su origen, a través de los datos arqueológicos aportados por numerosos ejemplos de esta área. 
El cerro de El Molón se sitúa en el extremo noroccidental de la comarca de Requena-Utiel, integrada tras la conquista musulmana en el Šarq al-Andalus (Fig. 1,1). Administrativamente formaría parte de la cora de Santaveria, que llegó a englobar hacia el este los cursos medios-altos de los ríos Júcar y Cabriel, y, desde allí, por el río Magro, hasta alcanzar la depresión del río Turia. El cerro, con una importante fase prerromana, se reocupa nuevamente en un momento muy cercano a la conquista musulmana, ya durante la segunda mitad del siglo VIII d.C., bien atestiguado por el registro arqueológico. Sus condiciones topográficas inmejorables, al quedar delimitada en buena medida por abruptos escarpes, y su indudable valor estratégico favorecieron el establecimiento, en la parte alta de la muela, de un núcleo de población de cierta entidad, que ocuparía principalmente la amplia zona amesetada, de algo más de 1 ha, conocida como La Gallarda, que ofrecía unas condiciones óptimas para tal ubicación.

Aunque la existencia de materiales de época medieval era conocida, la importancia del asentamiento islámico no había sido valorada en su justa medida. Las primeras actuaciones en el cerro, durante 1981, sirvieron para señalar la presencia de cerámica medieval (Fletcher, 1982, 152 ss.), siendo la publicación de algunos de los materiales de superficie la que permitió precisar, aunque erróneamente, su fase medieval, entonces adscrita a los siglos XII y XIIII d.C. (de la Pinta y Tolosa, 1980, 90 ss.; de la Pinta et alii, 198788, 299 ss.). La intervención llevada a cabo por J. M. Martínez, en 1992, proporcionó, del mismo modo, material cerámico medieval, que sería encuadrado entre los siglos IX y XIII (Martínez, 1992, 9 y 11). Desde $1995^{\circ}$, un equipo de la Universidad de Alicante y de la Universidad Complutense de Madrid dirige los trabajos arqueológicos, que han posibilitado conocer el origen, desarrollo y abandono de las diferentes fases del poblado, descubriendo parte de los restos defensivos y de habitación, tanto de época prerromana como medieval (Almagro-Gorbea et alii, 1996; Lorrio et alii, 1999; Lorrio, 2001; Lorrio y Sánchez de Prado, 2004; idem, 2007; Lorrio, 2007), siendo las últimas campañas de excavación las que han puesto al descubierto la planta completa del poblado islámico, cuyos restos eran visibles en superficie. La identificación en 2001, en la antigua zona de la acrópolis prerromana, de una mezquita (Lorrio y Sánchez de Prado, 2004), ha permitido reinterpretar el conjunto con una nueva perspectiva, valorando la importancia del asentamiento, que enlaza con aquellos otros localizados en las tierras del interior del Levante peninsular, aunque en este caso la

8. Los trabajos son financiados por la Dirección General de Patrimonio de la Comunidad Valenciana, así como por el M.I. Ayuntamiento de Camporrobles, a quienes agradecemos su incondicional apoyo y colaboración, que hacemos extensible al que fuera director de la Colección Museográfica Municipal, D. Raúl Gómez, verdadero impulsor de los trabajos arqueológicos en El Molón. existencia de un edificio dedicado al culto islámico nos permite identificar a sus pobladores, sin duda aquellas poblaciones beréberes que habitaron estas tierras montañosas del interior valenciano desde los primeros tiempos de la conquista ${ }^{9}$, siendo grupos tribales en permanente disidencia al control político de Córdoba, resistencia que, como apuntan algunos investigadores (Torró, 1998, 392 ss.), debía sostenerse en la existencia de una serie de fortificaciones -ma 'âqil y hușūn- en esta región.

Será, pues, la entidad del asentamiento medieval de El Molón, con su complejidad urbanística y sus defensas, aspectos que nos revelan su carácter estable, puesto igualmente de manifiesto a través de la singularidad de sus construcciones, destacando la presencia de una mezquita, pudiendo plantear su identificación como un hiṣn, un lugar fortificado en altura que habría de articular el poblamiento cercano entre un momento avanzado del siglo VIII y el X d.C. (vid. infra), encuadrándose, pues, en el período que Bazzana (1992, 55) denomina «Islámico antiguo».

\section{EL POBLADO ISLÁMICO Y SU ORGANI- ZACIÓN}

Elevándose sobre el terreno circundante, y extendiéndose a sus pies una extensa zona lagunar, El Molón albergó un asentamiento islámico que se va a circunscribir en gran medida a la cumbre de La Gallarda, donde todavía se conservaba en parte los restos de una destacada y compleja fortificación de época prerromana, como el tramo de muralla de más de $100 \mathrm{~m}$ en su lado norte, que enlaza con una potente torre y un antemural adelantado, mientras que al sur abruptos escarpes completaban la fortificación natural del sitio (Figs. 2 y 5,1), que presenta, en esta época, una clara organización tripartita:

\section{IV.1. LA MESETA SUPERIOR}

Esta zona, la antigua acrópolis prerromana, se rodeó de un muro perimetral que delimita un espacio, de unos $4.280 \mathrm{~m}^{2}$, en el que encontramos el poblado propiamente dicho (Fig. 2,1). El acceso se localiza

\footnotetext{
9. Como apunta Bazzana $(1992,27)$, siguiendo las tesis de P. Guichard, tres tipos de fuentes históricas muestran la intensa presencia de los beréberes en el Šarq al-Andalus: la toponimia y la onomástica, pudiendo, todavía hoy, relacionar el nombre de numerosas localidades con el de tribus beréberes, y, sobre todo, las referencias extraídas de las crónicas de la época, que llevan a plantear la profunda bereberización tanto de las llanuras levantinas, como de las montañas de Teruel y Cuenca (Guichard, 1995, 392 ss.), pues, desde la segunda mitad del siglo VIII, nos relatan algunos de los acontecimientos en los que participaron estas poblaciones, de carácter levantisco, como prueba algún relato sobre los enfrentamientos entre los de Balansiya (Valencia) y los de Santaver (780 d.C.).
} 

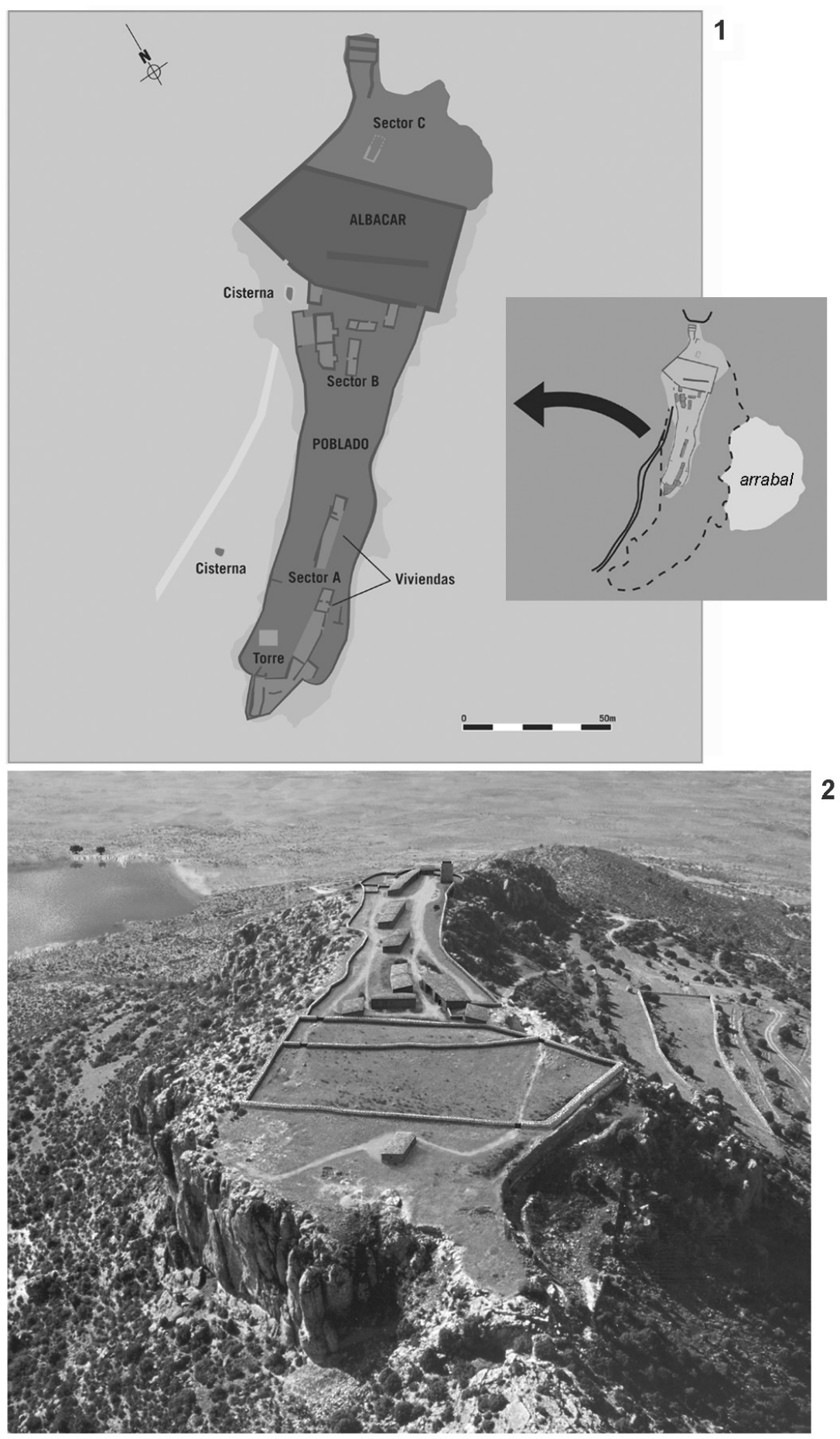

2

Figura 2: Planta del hiṣn de El Molón (1). Vista área ideal del poblado desde el Este (2).

en el extremo septentrional del recinto. Se llega desde la antigua puerta principal, que deja a la izquierda una cisterna tallada en la roca (Fig. 3,2 y 4) perteneciente a la fase prerromana, y posiblemente en uso también ahora; desde allí se sube, dado el desnivel que presenta esta zona por el afloramiento rocoso, por un estrecho pasillo, que va ascendiendo por un escalonamiento realizado en la roca natural. Este acceso queda cerrado al final del mismo por un muro, que configuraría una entrada acodada a un gran espacio abierto, de forma trapezoidal, delimitado, por el este, por parte del trazado rectilíneo del muro oeste de un recinto poligonal o albacar (vid. infra), al que se adosan dos de los edificios localizados en esta área, cerrándola por el norte y sur, mientras que, al oeste, se erigió otro edificio de disposición exenta, al tiempo que una estrecha calle de trazado irregular permite el acceso al gran edificio de la mezquita al 

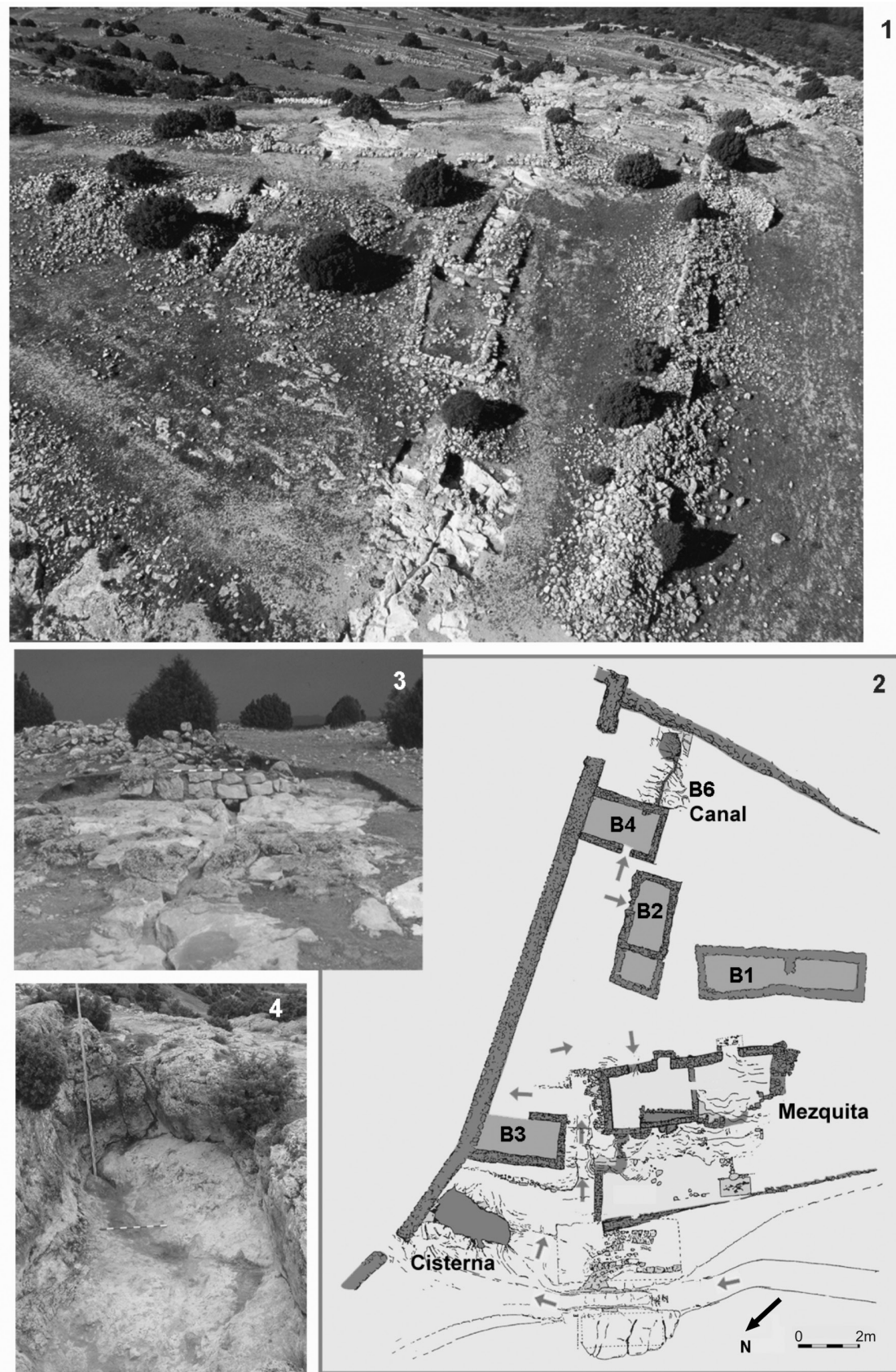

Figura 3: Foto áerea del sector B, desde el Sur (1) y planta del mismo (2). Detalle del canal rupestre (B6) del edificio B4 (3). Vista de una de las cisternas prerromanas, posiblemente en uso en época islámica (4).

norte, frente al que se localiza otro, que permanece sin excavar ${ }^{10}$.

10. La identificación de la mezquita en 2001, cuando ya se habían realizando diversas campañas en el sector que habían puesto al descubierto tres de los edificios, y dada la problemática de esta zona, nos llevó a desistir de su excavación, ya que por su localización, justo enfrente de este edificio religioso, debió desempeñar una importante funcionalidad, por lo que se ha reservado hasta tener datos suficientes para una mejor comprensión e interpretación del mismo.
En este sector B se localizan, pues, cuatro edificios que quedan organizados en torno a la mezquita. Se trata de estructuras habitacionales de planta rectangular simple (Fig. 3,1 y 3), cuyo origen parece estar en la casa berébere marroquí (Bazzana, 1992, 164), que, puede aparecer aislada, como en esta área, o integrada como elemento en una casa pluricelular, como veremos al tratar del sector occidental o sector A. Todos estos edificios presentan unas dimensiones similares, entre $6 \mathrm{~m}$ de largo y unos $3 \mathrm{~m}$ de ancho, con muros de mampostería de aparejo irregular trabado con barro que, de forma recurrente, van a reutilizar los muros de 
construcciones anteriores. Es característica la configuración del acceso, delimitado, a modo de jambas, por dos grandes piedras que vienen a ocupar el ancho del muro y se disponen a soga y tizón, dejando un vano de $1 \mathrm{~m}$ de ancho. La cubrición se realizaría con elementos vegetales, dada la ausencia de cualquier resto de derrumbe de teja ${ }^{11}$ en su interior, sin que se haya evidenciado de forma clara si la cubierta era a una o dos vertientes, habiéndose planteado cierta inclinación hacia el interior (Bazzana, 1992, 103). Los edificios, con un alzado todo él de piedra que conformaría hiladas horizontales más o menos regulares, se caracterizan por su aislamiento al exterior, siendo, generalmente, la puerta la única suministradora de luz hacia el interior. En cuanto a los suelos, no se ha documentado ninguna evidencia de pavimentos, por lo que serían de tierra apisonada, incluyendo residuos derivados de la actividad cotidiana, caracterizándose por su irregularidad, tanto en su espesor, composición o superficie, encontrándonos en algunos casos con la roca natural aflorando superficialmente. Aunque, como veremos posteriormente, las viviendas islámicas más comunes parecen configurarse mediante la yuxtaposición de varias estancias, es interesante señalar la documentación de edificios aislados, como los ubicados en este sector, en el poblado de Monte Mollet, donde se cita la presencia de un cierto número de construcciones rectangulares simples (Bazzana y Guichard, 1978, 494), que, del mismo modo, ofrecen otros poblados castellonenses de cronología algo más avanzada, como Zufera o Uxó II y III (Bazzana, 1992, 166).

En cuanto a su funcionalidad, estos edificios, dada su ubicación en el entorno de la mezquita y características constructivas, han de relacionarse directamente con este emblemático edificio, toda vez que la presencia de canales de desagüe, tan sólo documentados en dos de las construcciones de este sector -los departamentos denominados B4-B6 y B1-, podría sugerirnos su consideración como edificios provistos de un sistema de captación y distribución de agua, quizá evacuatorios o letrinas. En este sentido, destaca el edificio -B4-B6-, localizado al sur del espacio abierto o plaza (Fig. 3,2 y 3 ); de su esquina suroeste sale un estrecho canalillo de $0,12 \mathrm{~m}$. de ancho y 5,30 de largo, que, partiendo del interior de la estancia, atraviesa el muro meridional de la habitación en dirección sur, desaguando en una cubeta rupestre, de tendencia cuadrangular, con unas dimensiones medias de 1,10 m de lado. Este elemento podría evidenciar la existencia de un pequeño espacio, como una habitación independiente de reducido tamaño que albergaría una letrina en su interior, pudiéndose relacionar con el mismo una piedra perpendicular al muro sur, que podría considerarse como el único resto del muro

11. Como es habitual en estos asentamientos de primera época islámica hay una completa ausencia de la teja como elemento de cubrición, un uso que no se generalizaría hasta el siglo XI (Bazzana, 1992, 85). de compartimentación interna, un característico espacio que está bien documentado en la excavación de la casa 2 de la Plaza de Belluga de Murcia, correspondiendo a la primera fase del edificio, que dataría de los siglos X-XI d.C. (Jiménez y Navarro, 2002, 507, fig. 25), así como en las viviendas de Bayyana (Pechina, Almería) (Castillo y Martínez, 1990, fig. 6). En definitiva, un servicio que, destinado a la higiene, facilitaría la realización de ciertos actos de purificación menor, siendo imprescindible en el entorno de la mezquita.

Sin duda el edificio más emblemático del poblado es la mezquita (Lorrio y Sánchez de Prado, 2004). Presenta planta rectangular (Fig. 4,1), destacando la sólida construcción de la qibla, un muro de mampostería, con una longitud total de $16,50 \mathrm{~m}$ al exterior, integrado por diferentes tramos, técnica empleada únicamente para la construcción de este muro, el principal del edificio, cuya ejecución se llevó a cabo en primer lugar, consiguiéndose, de ese modo, un muro cortina cuyos vanos, de distintas dimensiones, se destinarán al acceso principal, el primero, de 1 metro de ancho, mientras que los otros dos configurarán sendos oratorios, el más occidental, desmantelado. El miḥrāb conservado ofrece planta cuadrangular, de esquinas redondeadas, construido con un doble paramento, que sobresale 0,87 y $0,76 \mathrm{~m}$, respectivamente, y presenta una longitud externa de $2 \mathrm{~m}$, configurando su interior un espacio con unas dimensiones de 1,50 por 1,25 m. Hay que señalar la presencia de dos pequeñas lajas dispuestas en los ángulos que reforzarían la unión con el propio muro de la qibla (Fig. 4,B); del otro, el más occidental, tan sólo resta la interrupción entre los diferentes tramos del muro, que, aunque en un principio fuera interpretada como otra entrada al edificio, dadas sus dimensiones, mayores a las de cualquier acceso documentado, ya que presenta un vano de $1,70 \mathrm{~m}$, quizá habría de identificarse como un segundo miḥrāb, prácticamente desmontado en su totalidad, pudiendo reconstruirse a partir de algunas piedras dispersas, que parecen formar un espacio cuadrangular, de 1,70 por 1,50 m, similar por tanto al del primer oratorio.

Partiendo de tal supuesto, el edificio presentaría, pues, dos salas, provistas cada una de ellas de un $m i h r a \bar{a} b^{12}$, que quedarían comunicadas a través de un

12. La presencia de dos oratorios en un mismo edificio es inusual. En el complejo de La Rábita de Guardamar, donde encontramos algunos edificios muy similares al nuestro, los diferentes oratorios se adosan, tratándose de espacios individualizados, provistos, cada uno de ellos, de su propio acceso (Azuar, 2004). Ello hace que no podamos descartar totalmente que el segundo fuera en realidad una entrada, lo que conferiría a la «sala oeste» una diferente funcionalidad, quizás una habitación destinada al albergue o acogida. Sin embargo, la escasez en la documentación de este tipo de construcciones en el medio rural y con una cronología similar, plantea la posibilidad de encontrarnos con una edificación singular cuyo espacio interior se hubiera adaptado a unas necesidades concretas de su población. 

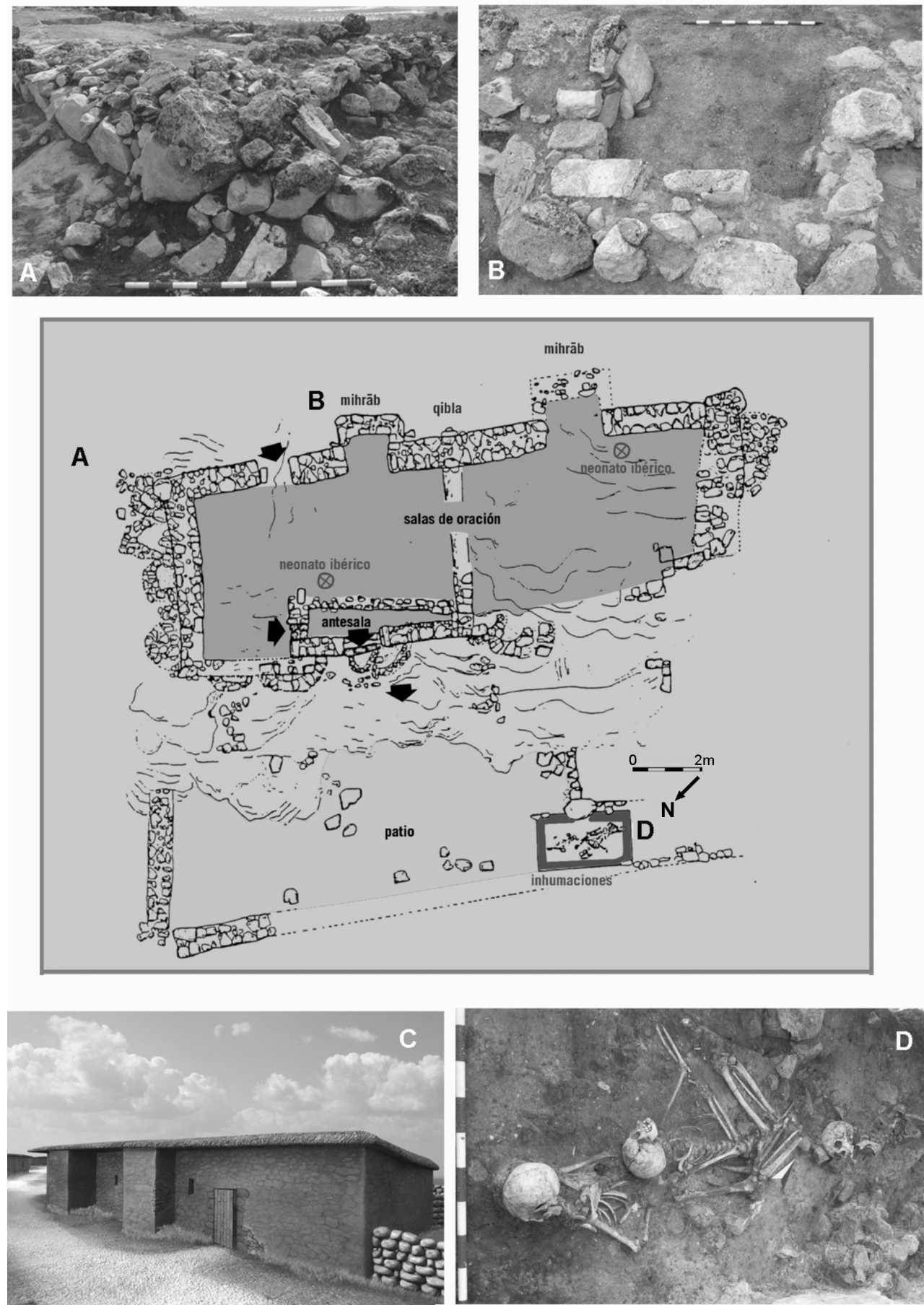

Figura 4: Planta de la mezquita (1). Detalle de la técnica constructiva de la esquina este (A) y del mihrāa (B). Restitución ideal del edificio (C). Detalle de los restos humanos documentados (D).

espacio creado al desmantelar la parte central de un muro de la fase prerromana, del que se conservan restos bajo la qibla y en su parte norte, donde se aprovecha como cierre oeste de la antesala. Las dos salas ofrecen una planta de tendencia rectangular y similares dimensiones, unos $7 \mathrm{~m}$ de largo por unos 4 de ancho ${ }^{13}$,

13. Resulta inhabitual el ancho que ofrecen las salas, pues, por ejemplo, los oratorios de La Rábita de Guardamar presentan unas dimensiones algo inferiores a los 3 m (Azuar, 2004). constituyendo el área sacra o principal del edificio. Una de las partes más características de la mezquita es la antesala, construida parcialmente en el interior de la sala este, a la que resta cerca de un metro de anchura en su parte oeste, confiriéndole una planta irregular. Presenta

Sin embargo, la construcción de la antesala en el interior de la sala este le restaría anchura, ajustándose a la media, de unos 3,30 m, que, según señala Bazzana $(1992,166)$, ofrecería la característica vivienda rectangular islámica. 
forma trapezoidal y unas dimensiones reducidas - unos $4 \mathrm{~m}$ de largo por 1 en su parte más ancha-, habiéndose construido aprovechando otros restos constructivos de la fase prerromana. La antesala, con sus reducidas dimensiones y singular disposición dentro del edificio, cumple una doble función. Por una parte, impide la visualización directa del mihrāab desde el exterior ${ }^{14}, \mathrm{y}$, por otra, debe considerarse como una zona de paso desde una de las salas al patio, situado al norte, al que se llegaría descendiendo por una serie de escalones realizados a fin de salvar la pronunciada pendiente de la zona.

La mezquita de El Molón (Fig. 4,C) se alzó en la parte más alta de la acrópolis, donde se planteó, en primer lugar, la qibla, o muro orientado hacia el Sureste, que se caracteriza por presentar, en general, ausencia de cimentación, levantándose directamente sobre los restos de dos viviendas de la fase prerromana ${ }^{15}$. La técnica constructiva utilizada en el edificio es la mampostería trabada con barro, no quedando evidencia de ningún tipo de enlucido. La qibla ofrece un mayor cuidado en su construcción, destacando su mayor anchura, que alcanza los $0,75 \mathrm{~m}$, similar a la de los muros con los que traba, que aparecen sistemáticamente reforzados por el exterior y en su cimentación por estructuras semicirculares, que también se encuentran en las esquinas, formadas por grandes bloques de piedra, reforzados, a su vez, por otras de menor tamaño a modo de calzos (Fig. 4,A). En cuanto a la cubierta, hay que mencionar la ausencia de cualquier evidencia de la misma, hecho que se repite en otros edificios similares, para los que se ha propuesto una cubierta vegetal aplanada, como los del complejo de La Rábita de Guardamar (Azuar, 1989; Azuar et alii, 1988-90, 61 ), algunos de los cuales, como los oratorios M-VI, M-VII, M-IV, M-II o M-XVIII, resultan iguales al nuestro, siendo construcciones todas ellas que presentan la entrada por la qibla, así como una estructura del $m i h r a \bar{a} b$ muy parecida, y que se encuadran en la primera fase de este complejo, fechada en un momento anterior al 944 (Azuar et alii, 1988-90, 62; Azuar, 2004, 53 s., fig. 43) ${ }^{16}$.

14. Parece ser característico, en los edificios de las mezquitas, el que los vanos se encuentren descentrados respecto al eje del mihrāb, pretendiendo con ello, según Azuar et alii (1988-90, 57), proteger su «condición sagrada», que, de ese modo, como se ha constatado en todos los oratorios de La Rábita de Guardamar, queda desplazado respecto a los accesos, tanto desde el exterior como desde el interior. Otro punto de vista es el aportado por Izquierdo y Prieto (199394, 26), quienes, al estudiar la mezquita de Vascos, explican el descentramiento que se percibe igualmente entre los vanos y el mihrāab, como un intento de resguardar la intimidad de ese espacio, al quedar oculto de la vista desde el exterior.

15. Es interesante señalar la documentación, bajo los niveles de suelo, de restos de enterramientos infantiles ibéricos que fueron localizados en dos puntos de las salas de oración.

16. En realidad, existe una gran dificultad a la hora de poder establecer un paralelismo exacto con otros edificios semejantes, ya que, aunque, en general, las mezquitas andalusíes
En el ángulo occidental del patio de la mezquita, muy próximo al muro perimetral que servía de cierre tanto del poblado como del propio edificio, se documentó, durante la campaña de 2002, una zona de enterramiento $^{17}$, que queda ubicada justo en la línea de pendiente, la cual ha acentuado la erosión de todos los restos emplazados en el área. Se trata de dos sepulturas (Fig. 4,D), una de ellas doble, carentes de cualquier elemento de ajuar. Su clara localización estratigráfica, por encima de los restos de las estructuras prerromanas, junto a la disposición de uno de los cadáveres, evidenciaba, sin género de dudas, su vinculación con

presenten rasgos comunes, es muy difícil encontrar construcciones iguales, pues suelen ofrecer alguna característica que las diferencie, a lo que se añade, por otra parte, los escasos edificios excavados o que, habiéndose conservado, hayan podido ser identificados como mezquitas.

En las tierras valencianas no se conservan evidencias de las antiguas mezquitas rurales, que, en los pocos casos documentados, presentarán importantes transformaciones tras la conquista cristiana (Bazzana, 1992, 239). Es el caso de la Iglesia de Miravet (Cabanes, Castellón), un edificio, cristiano, de planta rectangular $(13$ x 5,5 m) que queda dividida en cuatro espacios por tres arcos diafragmas, que en época islámica debió ofrecer un tamaño algo más reducido (unos 3,20 $\mathrm{m}$ de ancho), presentando en su muro sur un mihrāb, de forma absidal, y un pequeño nicho, estructuras inutilizadas tras su cristianización (Bazzana, 1992, 242, pl. CCLXIV). Otro ejemplo es el de la mezquita de Xara (Simat de Valldigna, Valencia), actual ermita de Santa Ana, también de planta rectangular, cuyo interior queda compartimentado en nueve espacios por una doble arcada que se apoya sobre cuatro pilares centrales, el mihrāb orientado al sureste y la entrada en el lado opuesto, actualmente tapiada (Bazzana, 1992, 242, pl. CXXIV). En realidad, dos ejemplos que siguen las bases arquitectónicas toledanas, y ofrecen un mihrāb absidado, lo que las aleja de la mezquita de El Molón. Otra mezquita rural, aunque igualmente de cronología más avanzada, es la documentada en Sa Nitja (Menorca), que ofrece una planta rectangular y del mismo modo un mihrāa de planta semicircular, ofreciendo los restos de otra estructura adosada a la sala principal, una habitación de funcionalidad indeterminada (Kirchner, 1999, 692). Hacia el siglo X se encuadra una mezquita identificada en la ciudad de Vascos (Navalmoralejo, Toledo), que ofrece planta cuadradatrapezoidal, con dos estancias comunicadas entre sí por una puerta interior, abierta en la parte central del muro que las separa, situándose una al norte (la antesala) y otra al sur (la sala principal o de oración), en cuyo muro sur se abre el $m i h r a \bar{b}$, que, en origen debió presentar forma cuadrangular, luego reformado para adoptar forma absidada (Izquierdo y Prieto, 1993-1994, 21 ss., fig. 1).

17. La localización de estos enterramientos permitiría plantear la existencia de un pequeño panteón en el interior del edificio de la mezquita, en este caso en la zona considerada como el patio, pudiendo estar ante la tumba de un personaje venerado por el grupo social: el santón. A este respecto, cabe señalar que la excavación de la zona localizada inmediatamente al este no ha deparado resto alguno de enterramientos, reduciéndose la información funeraria, por tanto, a los individuos descritos. 
la ocupación islámica del cerro, lo que ha sido confirmado por la datación radiocarbónica del individuo adulto de la sepultura doble (Lorrio y Sánchez de Prado, 2004, 156 s.), que ha proporcionado una fecha de $1260 \pm 40 \mathrm{BP}$ (Beta-183527), que calibrada a 2 sigma da el intervalo de 670-880 cal AD (770 cal AD m).

Las inhumaciones se encuentran dispuestas en dos conjuntos diferenciados, sin que haya podido distinguirse fosa alguna. El primer conjunto está formado por dos individuos inhumados sincrónicamente: el primero, un adulto, posiblemente una mujer, fue depositado en decúbito lateral derecho, estando orientado hacia el sureste, esto es, con una disposición paralela a la de la qibla, sobre él, un individuo joven en decúbito lateral izquierdo flexionado. Ambos cadáveres estaban cubiertos por un encachado de lajas de piedra sin desbastar, que posiblemente sirvieran para la inmovilización de los cuerpos, a fin de permanecer en la posición en que habían sido colocados.

La segunda sepultura, posterior ya que parece romper la tumba anteriormente descrita, se conserva de forma parcial, aunque pudiera haber tenido una orientación similar a la del adulto de la sepultura doble; al igual que aquellos, el cadáver estaba protegido por algunas piedras dispuestas, en este caso, sin orden aparente.

El estudio osteoarqueológico (de Miguel et alii, e.p.) ha permitido constatar restos de tres lesiones de origen traumático, todas ellas con signos de curación, en el individuo femenino, mientras que el varón adulto presentaba enfermedad periodontal, caries, fístulas alveolares y pérdidas dentales, lo que se relaciona generalmente con dietas ricas en hidratos de carbono, al igual que con hábitos higiénicos inadecuados.

Por su parte, y a diferencia de la anterior, en la zona más occidental o sector A (Figs. 2,1 y 5,1), se documentan, en la parte sur, dos conjuntos de edificios, al que habría que añadir un tercero, sin excavar, formados por varias estancias rectangulares. A partir de un muro de gran longitud, el muro trasero, se van a establecer los diferentes espacios de habitación, quedando adosados o ligeramente separados unos de otros. El sector ha proporcionado los restos de varias estancias, que formarían parte de distintas casas, posiblemente pluricelulares, dados algunos restos de muros que se conservan de forma muy parcial entre éstas y el muro perimetral, que discurre al sur de las mismas. Algunas muestran un estado muy deteriorado, concretamente las localizadas en el conjunto más oriental, no pudiéndose precisar dónde se situaría el acceso, al faltar el muro meridional, donde se localizan los vanos. Diferente es el conjunto que constituye el barrio más occidental, donde la conservación, aunque siempre a nivel de cimentación, es completa, observándose un urbanismo complejo de estancias que alternan con otras estructuras situadas por delante de las mismas, aunque lamentablemente muy deterioradas, lo que impide una correcta topografía e interpretación de los restos. En general, las estancias mejor conservadas presentan una orientación longitudinal Este-Oeste y el acceso hacia el sur, donde se localizan las características jambas monolíticas, que posiblemente dieran a un gran espacio abierto, un patio interior, que funcionaría como distribuidor hacia otros de trazado más irregular, al estar condicionadas tanto por el paramento interno del muro perimetral como por la irregularidad del terreno, encontrando diversos edificios distribuidos por las diferentes curvas de nivel del lado oeste. Por otra parte, es interesante señalar algunas remodelaciones arquitectónicas como las documentadas en el departamento A1 (Lorrio y Sánchez de Prado, 2007, 76 s.) que ha permitido constatar dos fases constructivas (Fig. 5,2). Tales remodelaciones se concretan en la eliminación del muro medianero entre dos de las estancias contiguas -A1 y A1.1-, el cegado de uno de los accesos (Fig. 5,4 ) y la habilitación de un pequeño espacio que queda separado del resto por dos tabiques construidos sobre los niveles de relleno acumulados en su interior (Fig. 5,3).

En general, la disposición urbanística que ofrece este sector parece responder a un tipo de viviendas, compuestas de diversos espacios que se yuxtaponen $\mathrm{y}$ presentan diferentes funcionalidades, pudiendo adoptar diferentes formas, como por ejemplo en «L» o «U», que ya resulta habitual en los poblados islámicos cuya construcción se plantea en los momentos cercanos a la conquista árabe, como en Monte Mollet y Monte Marinet, fechados hacia el siglo IX d.C., donde se han registrado estas viviendas configuradas por varias estancias adosadas en torno a un patio (Bazzana, 1986b: 150ss.; Bazzana, 1992, pls. CCLXVI y CCLIX, respectivamente).

Todos estos conjuntos de edificaciones se emplazan en la mitad meridional de la plataforma, quedando la zona norte como un área de circulación. En ella podemos señalar la existencia de una caseta (Figs. 2,1 y $5,1)$, muy remodelada, pues sirvió de puesto de control de un aeródromo cercano durante la Guerra Civil de 1936-1939, y cuya cimentación, sobresaliente sobre la línea de la pared, podría plantear la conservación de los restos de una pequeña torre de vigilancia, erigida en el punto más elevado, desde donde ejercería un control visual sobre el territorio circundante.

\section{IV.2. LA ZONA CENTRAL: EL ALBACAR}

Esta zona, complementaria y contigua al poblado, aparece rodeada por un muro perimetral a modo de muralla, que delimita un espacio, de unos $2.700 \mathrm{~m}^{2}$, pentagonal y de lados desiguales, en el que está ausente cualquier resto de construcción, salvo por un muro de trazado oblicuo que lo subdivide internamente (Fig. 6,1). El recinto presenta dos accesos, el principal, de $1 \mathrm{~m}$ de ancho, muy deteriorado, se localiza cerca de la zona que da acceso al poblado (Fig. 6,B). Hacia el noreste, se localiza otro acceso, secundario, que comunica con la zona más oriental, constituido por tres hileras de 

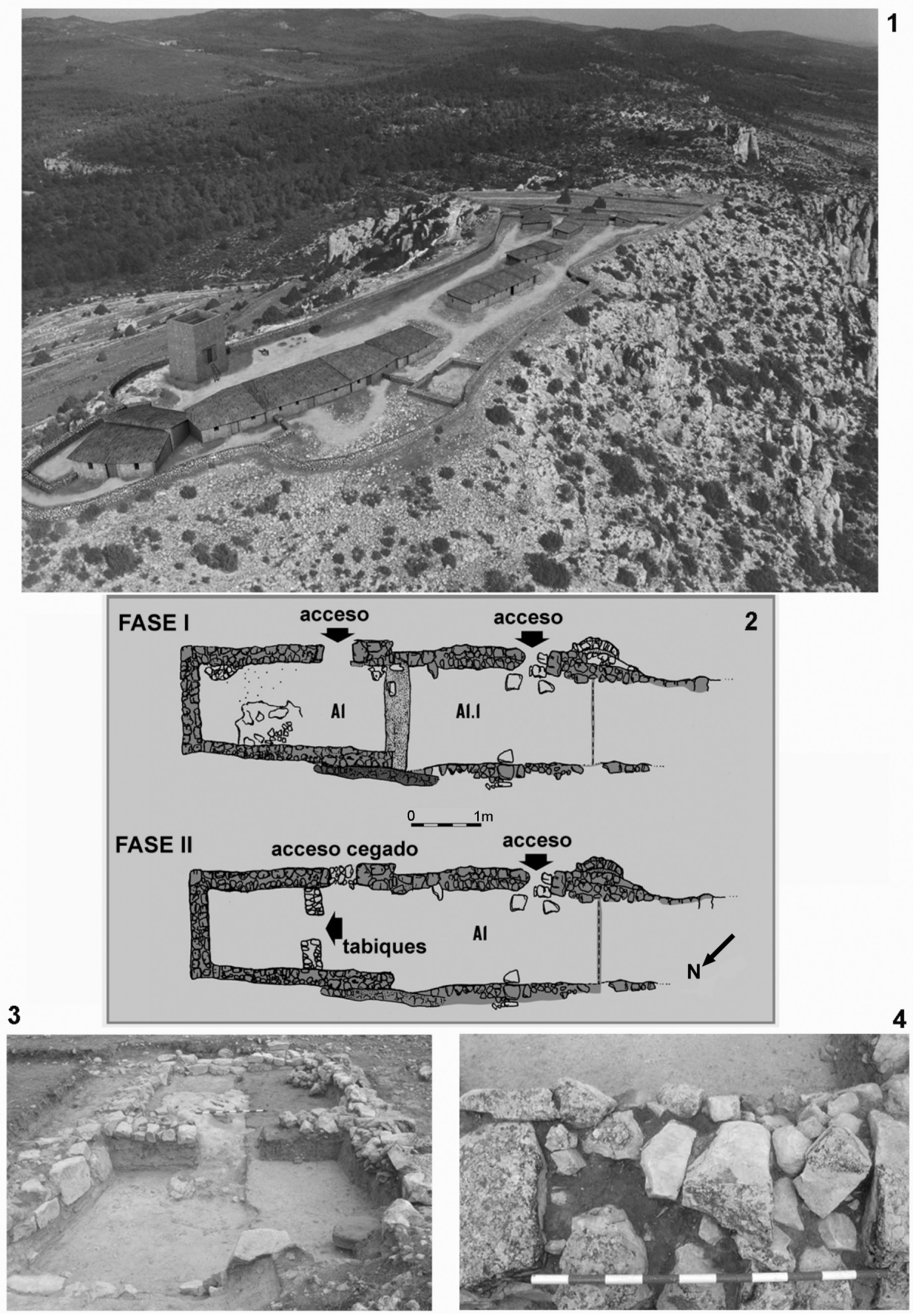

Figura 5: Vista aérea ideal del poblado islámico desde el Sur, con la zona de viviendas o sector A en primer término (1). Planta de las remodelaciones arquitectónicas documentadas en A1 (2). Vista del interior de la estancia A1, durante la Fase II (3) y detalle del acceso cegado (4).

losas dispuestas de forma escalonada (Fig. 6,D), que dejan un vano de $1 \mathrm{~m}$, y que, de este modo, salvan el desnivel entre las distintas plataformas.

Las labores agrícolas afectaron de forma importante a este sector, utilizando el muro interior así como el exterior más oriental como bancales para aterrazar la zona, convertida en campo de cultivo a partir de la década de los años 40 del pasado siglo; tales labores enmascararon la cara interna de los muros mencionados, localizada a casi medio metro de la superficie actual del terreno. Igualmente, con objeto de abrir caminos para el acceso de las caballerías y los aperos de labranza se desmontaron algunos tramos tanto de la muralla perimetral como del muro de compartimentación.

Los distintos tramos de este muro perimetral ofrecen una técnica constructiva muy simple, tratándose de un muro de doble paramento, realizándose la cara 

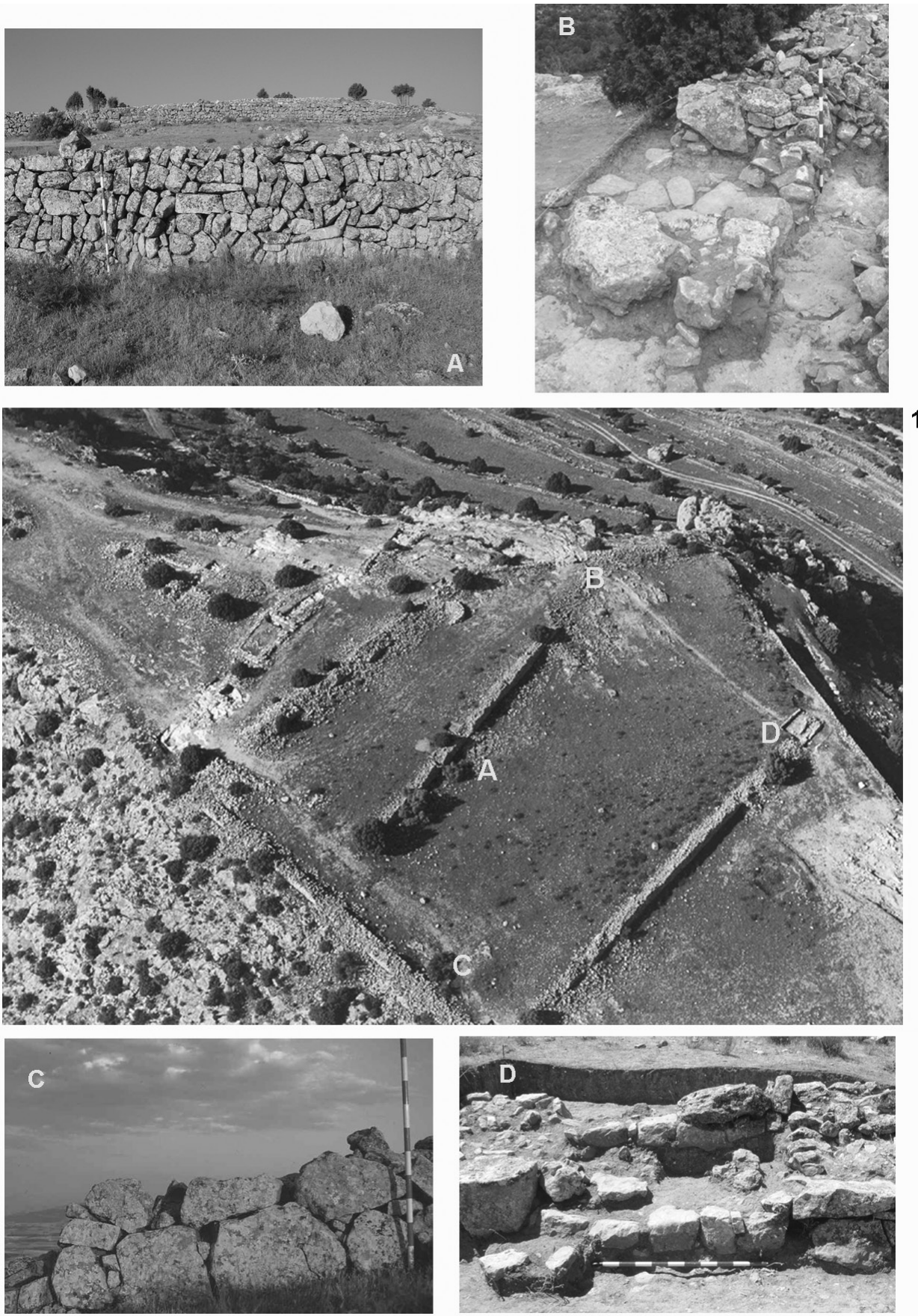

Figura 6: Vista aérea de la parte central del poblado con el albacar (1) y detalles de sus diversos aparejos (A y C) y de sus accesos (B y D).

exterior e interior con piedras de mediano tamaño, mientras que su interior se rellena con otras de menores dimensiones. Su anchura media varía entre 1 y $1,40 \mathrm{~m}$, conservando una altura de hasta $1,35 \mathrm{~m}$, alcanzada en ciertos tramos donde ofrece, entonces, hasta siete hiladas. Encontramos, en algunos puntos, piedras de gran tamaño para la cimentación (Fig. 6,C), sobre la que se disponen hiladas constituidas por otras de tamaño más pequeño, toscas y sin desbastar, presentando en algunos puntos un aparejo que recuerda una variante del opus spicatum, una sencilla disposición en oblicuo (Fig. 6,A) que no es sino una solución que permite el uso de piedra sin desbastar y de variados tamaños. En su cara norte utilizó como cimentación la muralla prerromana, lo cual ayudó a su preservación, limitándose en los demás a levantarse sobre los niveles de abandono de la ocupación precedente, incorporando, excepcionalmente, alguno de los sillares del sistema defensivo anterior, sin que en general llegara a asentarse sobre la roca base.

Esta amplia área, parte de la fortificación, que ocupa, en este caso una posición intermedia, se ha identificado como un albacar, dada su delimitación por un muro a modo de muralla y por la ausencia de 
construcciones en su interior, es decir por ser un «recinto vacío». Por lo que respecta a su funcionalidad cabría plantear dos opciones, no necesariamente excluyentes, pues mientras que Bazzana, Cressier y Guichard (1988, 29 ss.) defienden para estos espacios una funcionalidad defensiva, siendo un lugar que serviría, temporalmente, de refugio (Bazzana, 1992, 119), para otros (Epalza, 1984, 52; Gozalbes, 1987, 200) tendría una función socio-económica, como lugar destinado a la conservación del ganado, destinado al consumo de la población.

\section{IV.3. EL SECTOR ORIENTAL}

Este sector, al que se llega por el acceso escalonado del albacar, y abarca unos $1.807 \mathrm{~m}^{2}$, queda rodeado, hacia el norte, por las espectaculares defensas prerromanas, que, aunque en estado ruinoso, todavía conservarían gran parte de su alzado, mientras que, hacia el sureste, unos cortados verticales completarían su defensa natural. Se configura, por tanto, como una especie de fortín rodeado de un largo tramo de muralla y una potente torre, restos de las fortificaciones prerromanas parcialmente arruinadas, además de unos abruptos escarpes naturales.

El área, parcialmente excavada, parecía haberse destinado globalmente a algunos servicios derivados de las actividades cotidianas de los habitantes del poblado, habiéndose documentado la presencia de abundantes silos -14 hasta el momento-, cuyos diámetros oscilan entre 0,80 y $1,20 \mathrm{~m}$, que serían amortizados como basureros (Fig. 7,1 y 2). Aparecen rellenos de piedras pequeñas y tierra gris, habiéndose encontrado escasos restos cerámicos y de fauna. Además, en la zona se localizaban diversas placas de hogar, que se sitúan sobre las estructuras y rellenos de la fase prerromana. Presentan variadas dimensiones, tratándose de sencillas estructuras de barro que ofrecen la superficie quemada y endurecida por la acción calorífica. Destaca alguna de tamaño considerable, como la documentada en el pasillo de la antigua poterna del poblado, que ofrece un diámetro de 1,60 m, habiéndose encontrado en sus inmediaciones algunas cornamentas de bóvido. Sin embargo, durante las campañas de 2003-2004 se pudieron identificar los restos de una gran cisterna prerromana excavada en la roca natural, con una profundidad de $3 \mathrm{~m}$, cuya excavación permitió documentar, en su interior, los restos de un edificio de cierta envergadura de época islámica (Fig. 7,3), que, ocupando su mitad norte, presentaba unas dimensiones de unos $5 \mathrm{~m}$ de longitud por 3,5 de ancho, orientado, como parece habitual, hacia el sur, donde se localiza el acceso, de $1 \mathrm{~m}$ de vano, delimitado por dos potentes bloques monolíticos que ocupan todo el ancho del muro, que, en este caso, ofrece unas dimensiones de unos $0,70 \mathrm{~m}$, superior, pues, a las dimensiones mostradas por los muros de los otros edificios del poblado. Por su parte, el muro norte aprovecha como cimentación la antigua línea de sillares que revestirían la obra hidráulica. Otra singularidad respecto al resto de edificaciones es la presencia de una placa de hogar en su interior, ubicada en la parte central del lado este. El edificio, una vez abandonado, aparecía cubierto por dos grandes amontonamientos de piedras que sellaban dos basureros, correspondientes a la última fase del poblado. El interés por la reocupación de este espacio con una funcionalidad diferente a la tenida en época prerromana -por el contrario, la cisterna localizada junto a la entrada y, posiblemente, la conocida como «pozo de los moros», en el camino de acceso, mantuvieron su uso como aljibes también durante esta etapa- ya se documenta desde el primer momento de la presencia islámica en el cerro, compartimentándose su interior con muros de mampostería adosados a las paredes de la cisterna talladas en la roca, confirmando que ésta era aún visible, y hoyos de poste, restos de una posible estructura porticada indeterminada (Fig. 7,1).

\section{IV.4. LOS HALLAZGOS A EXTRAMUROS}

Finalmente, una zona de posible arrabal en la ladera sur, con una superficie de unos $12.175 \mathrm{~m}^{2}$, donde se ha localizado abundante material arqueológico islámico, así como restos de muros de mampostería, y una zona de cercados en la norte, con muros de doble paramento, donde se localiza, igualmente, una espectacular cisterna, cuya profundidad supera en la actualidad los $20 \mathrm{~m}$, lo que hace de ella una de las obras más espectaculares del conjunto arqueológico, completarían la organización de este hábitat (Fig. 2,1).

\section{ARTESANADO Y ECONOMÍA}

Los restos materiales que se han recuperado son enormemente monótonos, pues, a excepción de algunos objetos de piedra o metal, se reducen casi exclusivamente a materiales cerámicos, caracterizados, a su vez, por su estado fragmentario y homogeneidad, correspondiendo a las denominadas «ollas valencianas».

Los objetos metálicos registrados son muy escasos, pues dado el propio valor del metal, se reutilizarían de forma sistemática, habiéndose recuperado algunos cuchillos y clavos de dimensiones variadas, así como largas varillas, todo ello de hierro (Fig. 8,1,B-C). En cualquier caso la realización de actividades metalúrgicas en el asentamiento está plenamente confirmada por los restos de grandes bloques de escoria. También se han encontrado agujas en hueso (Fig. 8,1,A) que testimoniarían ciertas actividades textiles de carácter familiar. Finalmente, diversos útiles líticos, como percutores, pero también molinos, generalmente fragmentados y sin contexto, relacionados con labores de molienda, evidencian la realización de actividades agrícolas en el interior del poblado. 

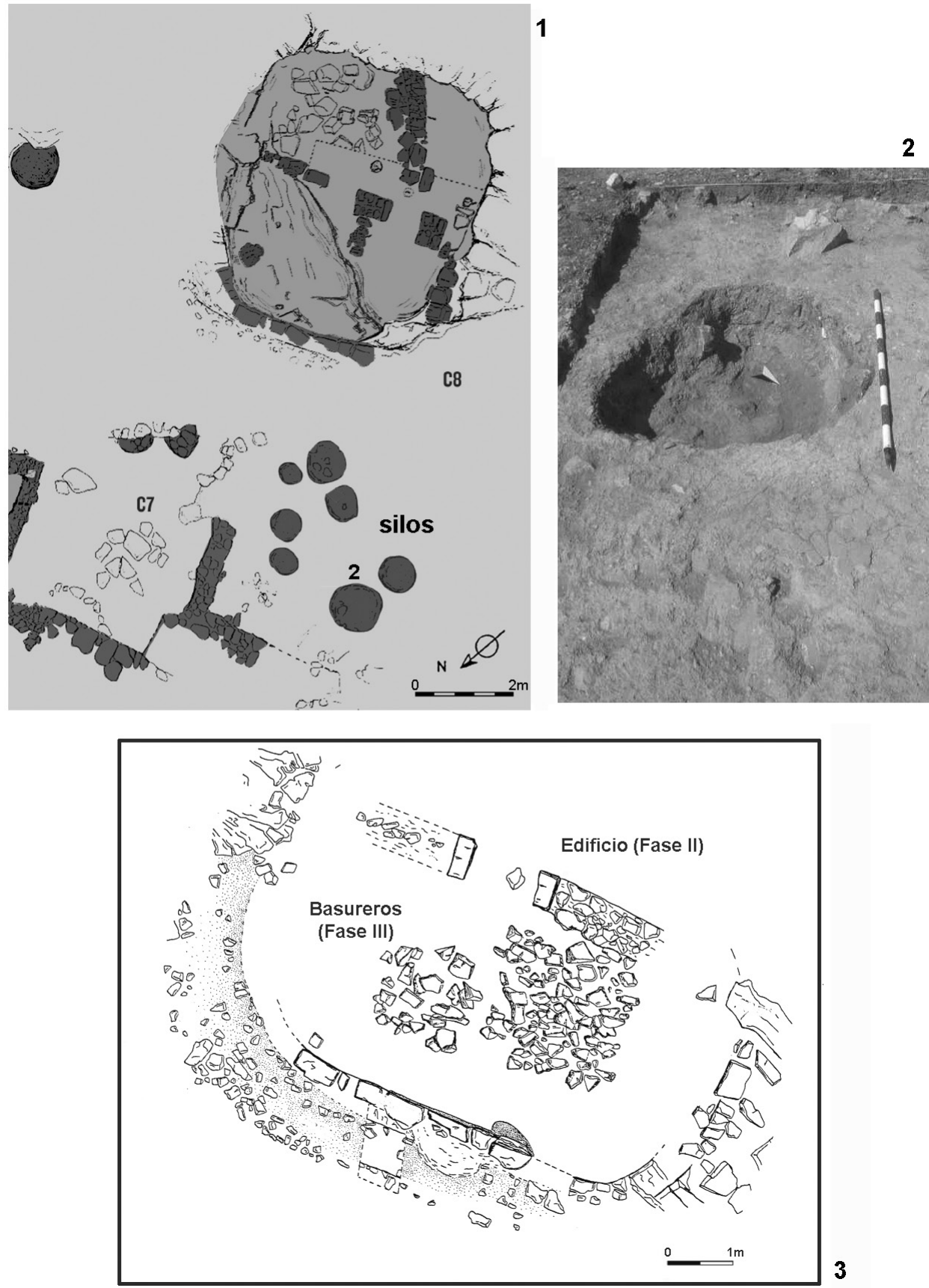

Figura 7: 1, Planta del sector oriental, con los restos constructivos identificados en el interior de la cisterna prerromana (Fase I) y de los silos documentados en la zona (2). 2, Detalle de uno de los silos y de una de las placas de hogar identificadas. 3, Planta del edifico construido sobre los rellenos de la antigua cisterna (Fase II) y los basureros correspondientes a su abandono (Fase III).

La población de El Molón debió de practicar una economía de subsistencia (Fig. 8,2) ${ }^{18}$, basada fundamentalmente en la ganadería de ovicápridos, rebaños mixtos con una mayor presencia de ovejas que de cabras, para su aprovechamiento cárnico y para la obtención de

18. Agradecemos a la Dra. P. Iborra los datos aportados sobre los restos de fauna que han permitido una aproximación al estudio económico de esta población. leche, lana y pieles, aunque también se hayan recuperado restos de bóvidos, que parecen ser explotados exclusivamente para su consumo. Los restos de cerdo son muy escasos, pudiendo tratarse, dada su condición de individuos jóvenes, de jabalíes. También está constatada la caza, con una preferencia por las especies de tamaño pequeño, como conejos y liebres, aunque también se abatirían ciervos. El aprovechamiento agrícola de las zonas llanas que rodearían las lagunas de Camporrobles completaría la base económica de estas poblaciones. 

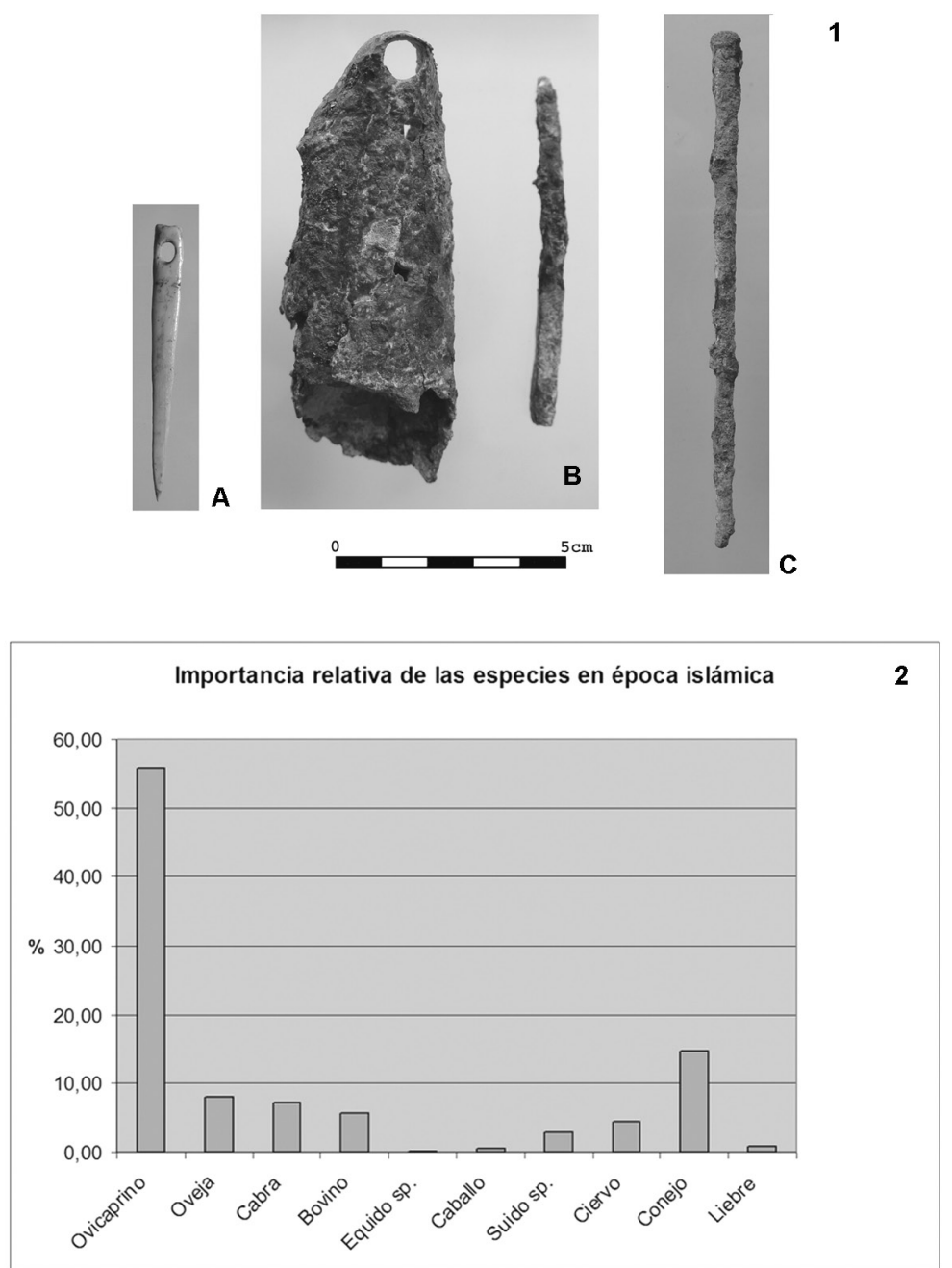

Figura 8: 1, El artesanado: Aguja de hueso (A), cencerro (B) y varilla (C), de hierro. La economía: Tabla de especies consumidas (2).

En este sentido, resultan de gran interés los estudios de paleodieta de los cadáveres enterrados junto a la mezquita (Trancho y Robledo, 2004). Los tres individuos analizados presentan un patrón económico esencialmente agrícola; con una dieta basada especialmente en los cereales, vegetales verdes y pescado, lo que cabe relacionar con la cercana zona lagunar camporruteña, actualmente desecada. Por el contrario, la ingesta de carne roja, frutos secos, legumbres, tubérculos y derivados lácteos era reducida.

Las necesidades de agua por parte de la comunidad asentada en El Molón se verían cubiertas con la existencia de dos cisternas talladas en la roca, las dos de época prerromana, aunque seguramente en uso durante la ocupación islámica del cerro, al tiempo que la situada en el interior del poblado, en el sector oriental, cambió de funcionalidad durante esta etapa, albergando, como se ha apuntado, un edificio de grandes dimensiones.

\section{V.1. LOS MATERIALES CERÁMICOS}

El predominio casi absoluto de un solo tipo cerámico como es la «olla» nos muestra un repertorio básico destinado a la preparación y conservación de los alimentos, que se acompañaría, posiblemente, de una vajilla en madera, de la que no han quedado vestigios. A pesar de su habitual registro en estado fragmentario, podemos distinguir diversas producciones.

Destacan marmitas u ollas que ofrecen una decoración incisa simple, como una simple línea ondulada bajo el borde, o peinada con motivos múltiples. Esta cenefa puede presentar distintas composiciones, alternando bandas de trazos rectos en horizontal con otras onduladas, es decir peinados mixtos. Los ejemplares registrados proceden, lamentablemente, de niveles que ofrecen escasa fiabilidad cronológica, al ser fruto de recogidas superficiales o de los rellenos de algunos de los basureros que señalan el abandono 
del poblado (Fig. 9,A,1-3), que han proporcionado, en general, una amplia muestra material que abarca la cronología general del yacimiento desde sus fases iniciales. Tanto el análisis tipológico de estas ollas como el de su patrón decorativo nos llevaron a apuntar ciertas similitudes con otras que se han registrado en contextos altomedievales como demuestran algunos tipos procedentes de La Alcudia (Elche, Alicante) (Fig. 9,B), donde encontramos ollas globulares de borde exvasado con una línea simple ondulada (Gutiérrez, 1988, AL17 y 18; Gutiérrez, 1996, fig. 75, forma M6), fechadas entre el siglo VI y mediados del VIII a.C., así como algunas de las ollas documentadas en la villa romana de L'Aiguacuit (Tarrasa), un yacimiento que ofrece una larga secuencia cronológica, en la que se han distinguido hasta cinco fases que abarcan desde época altoimperial hasta fines del X-XI d.C. (Coll et alii, 1997, 41 ss.). El análisis de las más tardías (Fase V, ss. VI-VII y Fase VI, altomedieval) ha permitido identificar dos basureros y diversos niveles de relleno de antiguos silos, encuadrados en la Fase $\mathrm{V}$ de este yacimiento que han proporcionado un abundante material, representado en su mayoría por ollas de cuerpo globular y bordes diversos, sobre todo moldurados, algunos decorados con líneas incisas paralelas y decoración peinada (Coll et alii, 1997, 43, fig. 11,1-5) (Fig. 9,C). Sin embargo, el peinado como motivo decorativo va a perdurar, como nos demostraría el que, en época califal, (s. X d.C.) se mantenga esta decoración sobre el tipo marmita y la olla de borde exvasado, que siguen mostrando bandas peinadas múltiples (Gutiérrez, 1996, figs. 81-82), formas que podríamos relacionar con algunos de nuestros fragmentos que han sido recuperados tanto en niveles a extramuros como en el relleno de algún basurero del sector oriental, correspondiendo a pequeñas marmitas (Fig. 9,A,4) u ollas con decoración peinada múltiple, alguna con pico vertedor (Fig. 9,A,5), mostrando, pues, parte del repertorio característico de la etapa final del poblado. Del mismo modo hay que señalar la documentación de una olla con decoración peinada (Fig. 9,D) entre las producciones del testar de Onda (Castellón) que debió funcionar entre los siglos IX-X d.C. (Montmessin, 1980), uno de los pocos centros alfareros conocidos que ha proporcionado, como veremos (vid. infra), una muestra de las diversas producciones destinadas al comercio local en esos momentos.

A pesar de haber señalado algunas producciones de cerámica común que ofrecen decoración, escasamente documentadas por otra parte, en general el material se reduce a una amplia muestra de cerámicas lisas, que parecen remitir, dados los paralelos registrados, ampliamente al siglo IX d.C. Por una parte, podemos señalar la presencia de algunas ollas o marmitas con dos asas, como algún ejemplar recuperado en el nivel de abandono de la primera fase islámica del sector A3 (Fig. 9,A,6) o de la superficie del poblado (Fig. 9,A,7) que recuerdan ciertas producciones de época emiral registradas en la provincia de Alicante (Gutiérrez, 1996, 178, serie T6, fig. 79); por otra, encontramos diversas jarras de cuerpo ovoide de cuello acanalado, con o sin pico vertedor, provistas de un asa (Fig. 9,A,8) que podríamos relacionar con algunas de las formas de la serie T18 de Gutiérrez (1996, 111, fig. 40). Además, y procedentes de los niveles superficiales, hay algunas ollas lisas de cuerpo más o menos globular u ovoide que ofrecen cierta diversidad formal en las bocas, con bordes exvasados o con inflexión interna (Fig. 9,A,9), cuya adscripción cronológica ofrece cierta complejidad al haberse relacionado con tipos de tradición visigoda (Álvarez, 1989, 121), aunque su documentación quede bien registrada hacia fines del siglo IX d.C., momento en el que se abandona el monasterio visigodo de Arcávica (Cuenca) (Álvarez, 1989, 109 ss.), y con el que se relaciona un lote cerámico que engloba un importante conjunto de ollas de diferentes tamaños cocidas en ambientes reductores y de aspecto tosco, además de alguna jarra (Álvarez, 1989, fig. 1), que guardan estrechas similitudes con nuestro material.

$\mathrm{Si}$ mayoritariamente el yacimiento ha proporcionado el tipo olla, hay que señalar la documentación, hasta el momento única, de un gran contenedor (Fig. 9,A,10), que apareció aplastado sobre una placa de hogar, en el sector B8, en las inmediaciones del edificio de la mezquita, que recuerda la forma 1 de la serie T10 de Gutiérrez (1996, fig. 32), un recipiente de gran tamaño y boca estrecha y cuerpo de tendencia ovoide, encuadrado, igualmente, en el siglo IX d.C.

Sin embargo, dentro de la categoría de las ollas registradas hay que destacar un grupo muy homogéneo que, aunque constituido por pequeños fragmentos de bordes y bases, planas o convexas, podemos identificar sin duda alguna con el tipo conocido como «olla valenciana». Se trata de un recipiente con fondo convexo, paredes de irregular grosor, más o menos delgadas, cuerpo de tendencia globular y borde exvasado, donde presenta una zona de acanaladuras irregulares que se extienden por los hombros; en algunos casos presentan asas. Las pastas suelen presentar una coloración que alterna desde el gris al ocre. En cuanto a su superficie, es característico el tratamiento de arrastrado que muestran en la parte inferior de la panza, que produce rayas y oquedades, resultado del fuerte raspado, dirigido a adelgazar sus paredes (Bazzana, 1986a). Este tipo cerámico es frecuente en algunos poblados islámicos del interior del Levante, pudiendo destacar su presencia en los yacimientos valencianos de El Castellar de Meca (López, 1985, 186; Bazzana, 1992, 409), así como en Alcira y la propia ciudad de Valencia (Bazzana, 1986a, 95, figs. 2-3), o en los castellonenses de Monte Mollet o Monte Marinet, poblados estos últimos donde alcanza unos altos porcentajes, cercanos al $90 \%$ de la producción cerámica total (Bazzana, 1992, 146 s., Tablas 5-6).

La identificación en El Molón de este tipo de ollas, actualmente en proceso de estudio, ha permitido proponer distintas variedades: 
A
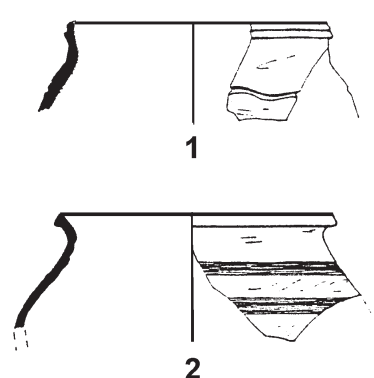

2

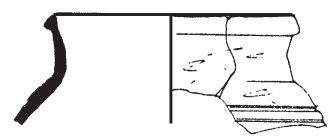

3

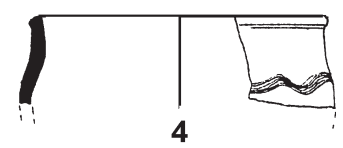

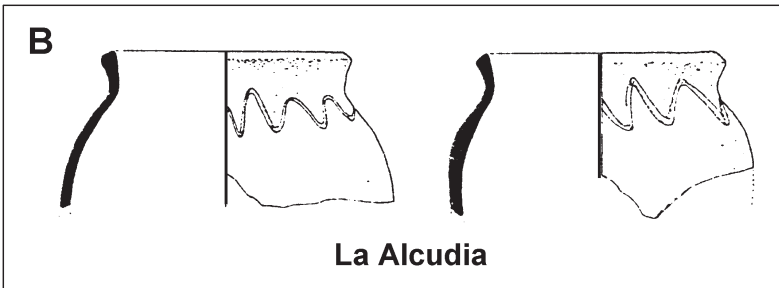
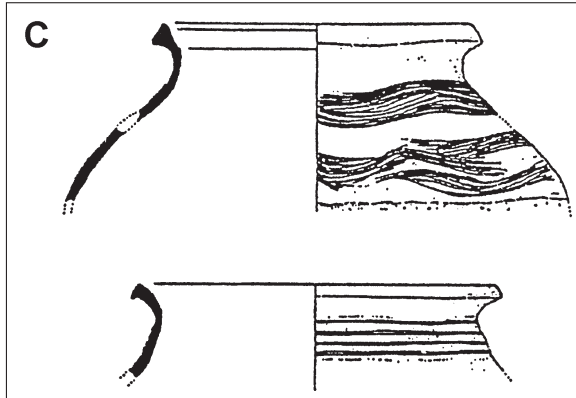

L’Aiguacuit (Tarrasa)

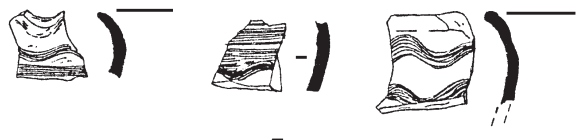

5

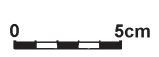

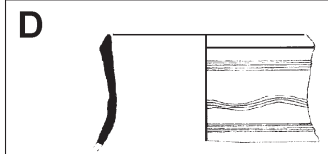

Testar de Onda
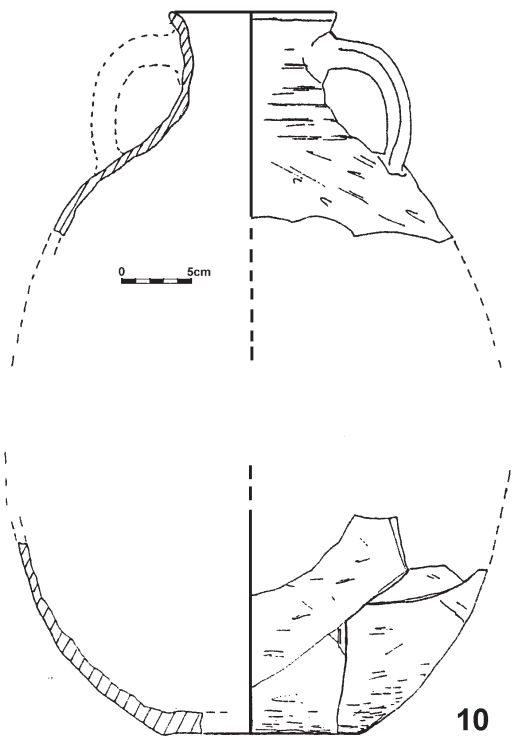

Figura 9: A, La cerámica común de El Molón: Producciones con decoración incisa (1-5) y lisas (6-10). Cerámicas incisas de La Alcudia (B), L'Aiguacuit (C) y el testar de Onda (D) (Según Gutiérrez, 1988 (B), Coll et alii, 1997 (C) y Montmessin, 1980 (D)).

Variante 1. Se trata de una olla, lamentablemente fragmentada en su parte inferior, que ofrece un acentuado borde exvasado y un cuello decorado con acanaladuras, correspondiendo al tipo I de Bazzana (1986a, 97), quien las considera de mayor antigüedad, situándolas entre los siglos VII y el IX d.C., habiéndose registrado tanto en Monte Mollet como en Marinet, asentamientos que no se prolongan más allá del siglo IX. Nuestros ejemplares, en general, proceden de niveles poco fiables, tanto superficiales (Fig. 10,A,2), como del nivel de derrumbe del edificio A1 -UE 127- (Fig. 10,A,1), correspondiendo a la segunda fase islámica detectada en esta estancia (Fig. 5,2). 


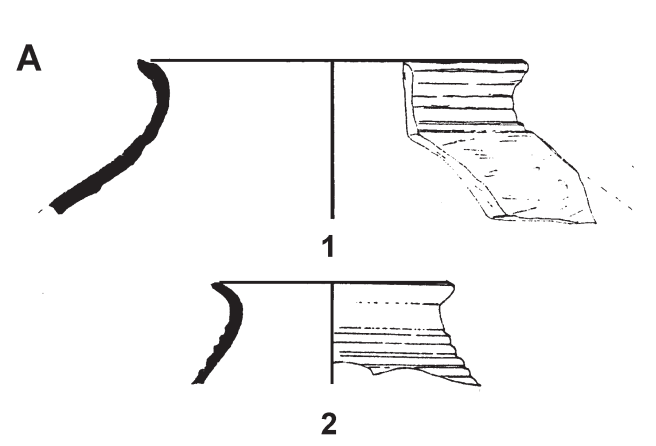

2

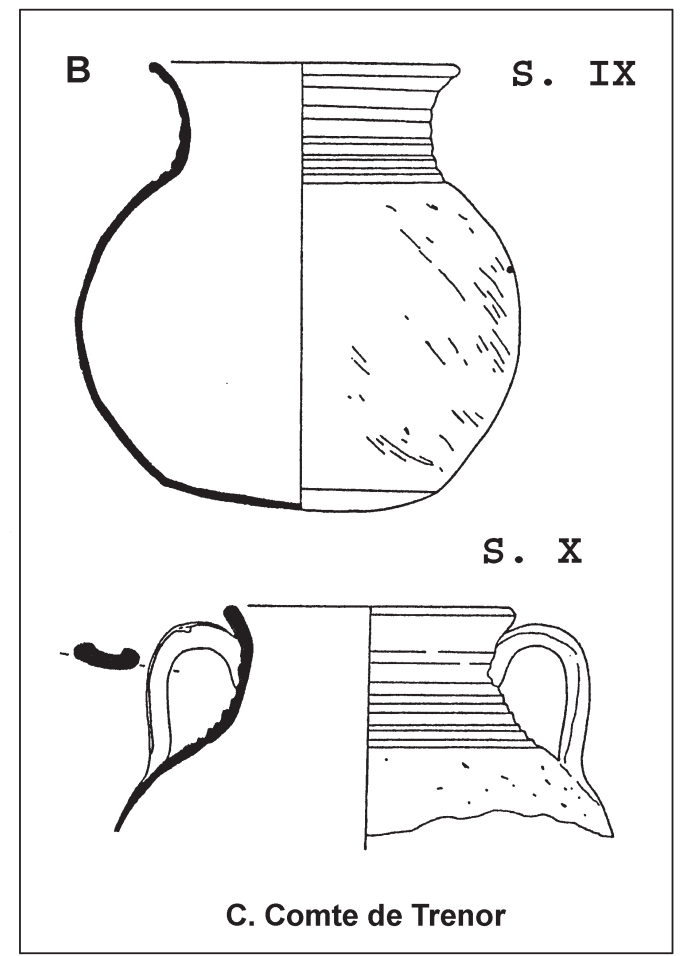

S. IX
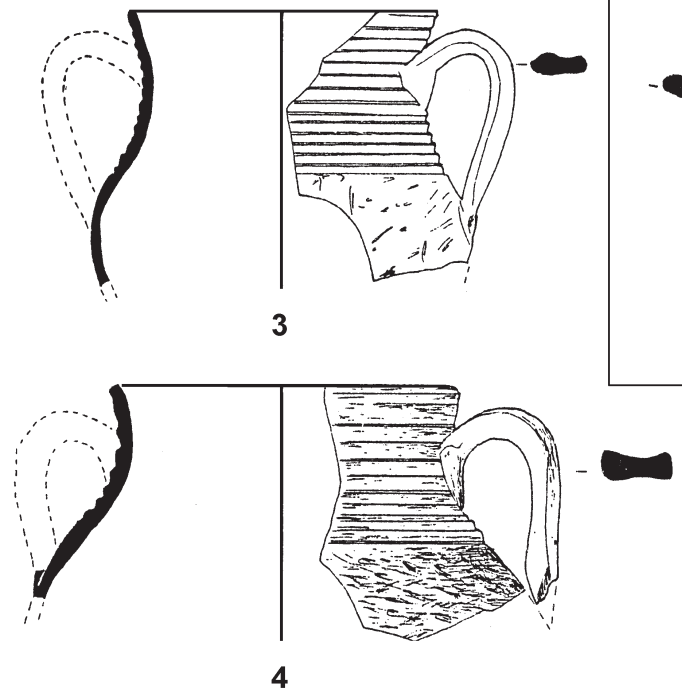

C. Comte de Trenor
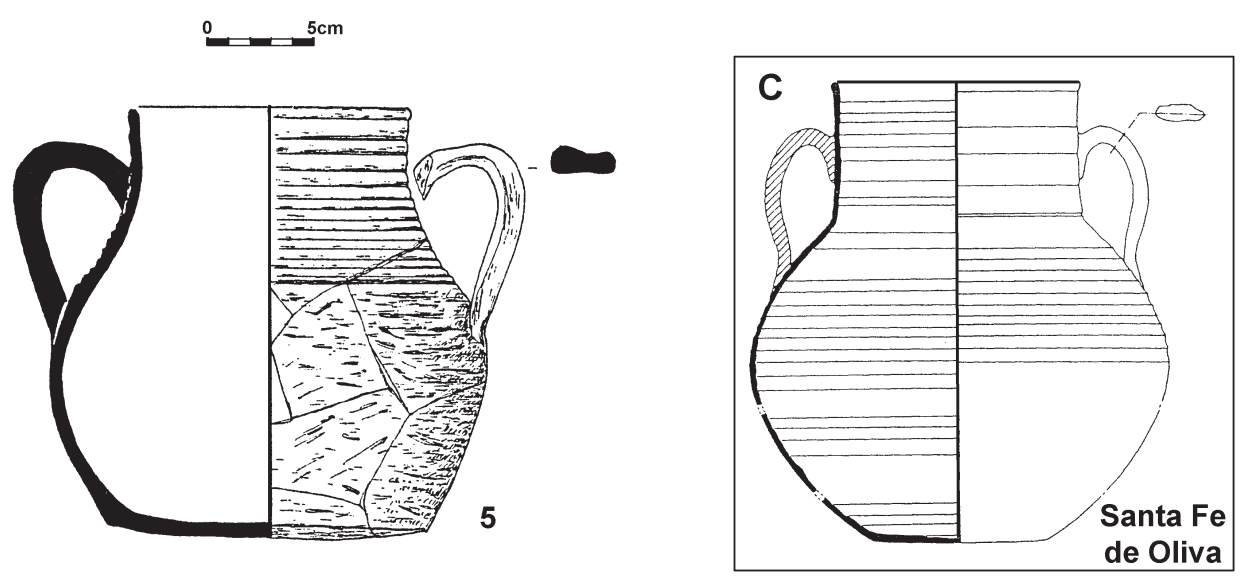

Figura 10: A, Las «ollas valencianas» de El Molón: Variantes 1 (1-2), 2 (3-4), 3 (5) y 4 (6). Ejemplos de algunas "ollas valencianas" procedentes de la excavación de la calle Comte de Trenor de Valencia (B) y del poblado de Santa Fe de Oliva (C) (Según Pascual et alii, 1997 (B) y Bazzana, 1984 (C)).

Variante 2. Ollas de cuerpo globular, provistas de un cuello de tendencia cilíndrica ligeramente exvasado terminado en un borde simple. El cuello aparece todo él acanalado, mientras que el característico raspado cubre la superficie de la panza. Esta variante presenta asas, aplicadas desde debajo del borde hasta los hombros, pudiendo relacionarse con el tipo IIb de Bazzana (1986a, 97). Se encuentra bien registrada en algunos de los niveles de las estancias del sector A, pudiendo destacar diversos ejemplares procedentes de la primera fase islámica detectada en la estancia $\mathrm{A} 1$, tanto en el nivel de suelo-UE 123-(Fig. 10,A,3), como del nivel de derrumbe-UE 116-; algún ejemplar procede, igualmente de los niveles superficiales de A2 (Fig. 10,A,4).

Variante 3. Se conserva una olla completa que ofrece un cuerpo globular y un cuello de cierta longitud, 
cilíndrico, rematado en un borde simple de labio redondeado, que muestra ya una clara tendencia hacia los cuellos rectos que van a caracterizar tipos más avanzados, que podríamos relacionar con algunos ejemplares del Grupo Valencia-Játiva (Bazzana, 1986a, 97 s.). La olla, que presenta una base aplanada y mantiene el característico perfil continuo, se ha documentado en el derrumbe de la estancia A2 -UE 214- (Fig. 10,A,5).

Variante 4. Asociado a la olla anterior, encontramos un nuevo tipo de recipiente, posiblemente un jarro, que ofrece un cuello alto y totalmente recto y un labio ligeramente biselado (Fig. 10,A,6), una forma bien documentada en los niveles de relleno de varios de los basureros relacionados con el abandono del asentamiento, estando, pues, ante uno de los tipos que representarían su etapa final.

Como se ha apuntado, las dos primeras variantes corresponderían a los tipos I y II de la clasificación realizada por Bazzana (1986a, 97), una forma cerámica frecuente en algunos poblados de las provincias de Alicante, como El Castellar de Alcoy, donde atestiguan la primera ocupación del sitio, y Valencia, pudiendo citar el de San Antoni d'Oliva, característico del siglo X d.C. y donde la forma olla resulta predominante (Bazzana, 1992, pls. CCXXXIII y CCLXXV, 1-5), además de los ya apuntados anteriormente (vid. supra), y, sobre todo, en otros de Castellón, donde resulta un hallazgo habitual, pudiendo señalar la cueva de Jualentejas (Fuentes de Ayodar), donde encontramos ollas con borde más o menos exvasado y también pequeñas tacitas con un asa (Bazzana, 1992,pl. CCXLVI, 1-2, 6-7 y 10-11), pero también un hallazgo que, en ocasiones, llega a ser casi exclusivo, como se constata a través del repertorio ofrecido por los poblados de Monte Marinet (Bazzana, 1986b, 157 s.; Bazzana, 1992, pl. CCLVII, 1-6) у Monte Mollet, donde es interesante apuntar que, junto a las características ollas globulares de borde exvasado y perfil continuo, encontramos la parte superior de otra que ofrece un elevado cuello cilíndrico con ligera tendencia troncocónica (Bazzana, 1992, pl. CCLXXII). Fuera de estas zonas, hay que señalar cómo nuestra variante 1 se ha documentado en el Tolmo de Minateda (Hellín, Albacete), en cronologías del siglo IX d.C. al asociarse a formas emirales (Gutiérrez, 1999, fig. 87). En este yacimiento se han podido registrar diferentes variantes de ollas que ofrecen cuellos de mayor o menor longitud (Gutiérrez, 1999, 80, fig. 12,1-5).

En cuanto a su encuadre cronológico, se trata de cerámica común sin ningún tipo de decoración, que suele encuadrarse, según Bazzana $(1986 a, 97)^{19}$, a par-

19. Como recoge Gutiérrez $(2000,241)$, la presencia de las ollas valencianas ha tendido a ser relacionada con el temprano poblamiento berébere de la zona donde son características, aunque, ciertos hallazgos de fines del siglo VI e inicios de VII d.C. en la ciudad de Valencia parecen atestiguar su origen preislámico, aunque hay que tener en cuenta su procedencia de niveles de contacto entre época islámica y visigoda, o rellenos de fosas de época tardorromana. tir del siglo VII d.C., como sugiere su presencia entre los materiales recuperados de un basurero documentado en La Almoina, la propia ciudad de Valencia, fechado hacia fines del VI-VII d.C. (Pascual et alii, 1997, fig. 8,12). Sin embargo, no parece que su origen preislámico esté definitivamente probado, siendo en los contextos emirales cuando nuestra variante 1 aparece de forma habitual, como demuestra su registro en el interior de una de las fosas de expolio documentadas en la calle Comte de Trenor de esa misma ciudad, que ha proporcionado un contexto encuadrado en la segunda mitad del siglo IX a.C. (Pascual et alii, 1997, fig. 10,1-2) (Fig. 10,B, arriba), lo que coincide con la cronología ofrecida por los contextos del Tolmo de Minateda, donde este tipo de olla no aparece en momentos anteriores, tratándose, sin duda de una importación desde regiones limítrofes (Gutiérrez, 1999, 81). Por su parte, estas intervenciones en la calle Comte de Trenor permiten establecer la evolución formal del tipo, ya que procedente de niveles superiores, que remiten al siglo X, encontramos la olla gris de cuello acanalado provista ahora de dos asas (Pascual et alii, 1997, 187, fig. 11,3), claramente relacionada con nuestra variante 2 (Fig. 10,B, abajo), señalándose la presencia de ollas con decoración pintada en óxido de hierro y la ausencia de piezas vidriadas.

El último estadio de las ollas valencianas recuperadas en El Molón queda representado por nuestra variante 3 , muy similar a una pieza completa procedente del Castellar de Alcoy, donde igualmente encontramos jarros con cuellos cilíndricos provistos de dos asas, que podrían relacionarse, a su vez, con nuestra variante 4 (Bazzana, 1992, pl. CCXXX,4 y 7), una forma ampliamente registrada en el poblado de Santa Fe de Oliva (Valencia) (Bazzana, 1984, 323, figs. 11-15 y 57) (Fig. 10,C), encuadrado entre fines del siglo $X$ y la primera mitad del XI d.C. (Bazzana, 1984, 335).

En definitiva, las ollas valencianas documentadas en El Molón ofrecen una serie de características que parecen marcar la evolución gradual del tipo, desde aquellas que muestran una amplia boca exvasada que continúa la curvatura del cuello, bien atestiguadas en contextos del siglo IX d.C., para en un estadio siguiente encontrar la típica olla de cuello acanalado y perfil continuo, ahora provista de asas aplicadas, que va ofreciendo progresivamente menos exvasamiento, tendiendo a altos cuellos cilíndricos, que encontramos ya en la forma olla o en el jarro, a partir del siglo X en adelante.

En general, la cerámica documentada en El Molón remite a producciones locales, como queda atestiguado por el material procedente del testar identificado en Onda/Mas de Pere (Castellón), donde se llevó a cabo una campaña de prospección que permitió obtener un buen lote cerámico, sin que se haya podido relacionar con estructuras ni horno alguno (Montmessin, 1980, 243 ss.). Entre las distintas formas registradas hay que destacar el gran volumen de ollas de cuerpo globular, fondo plano o convexo y labios que ofrecen 


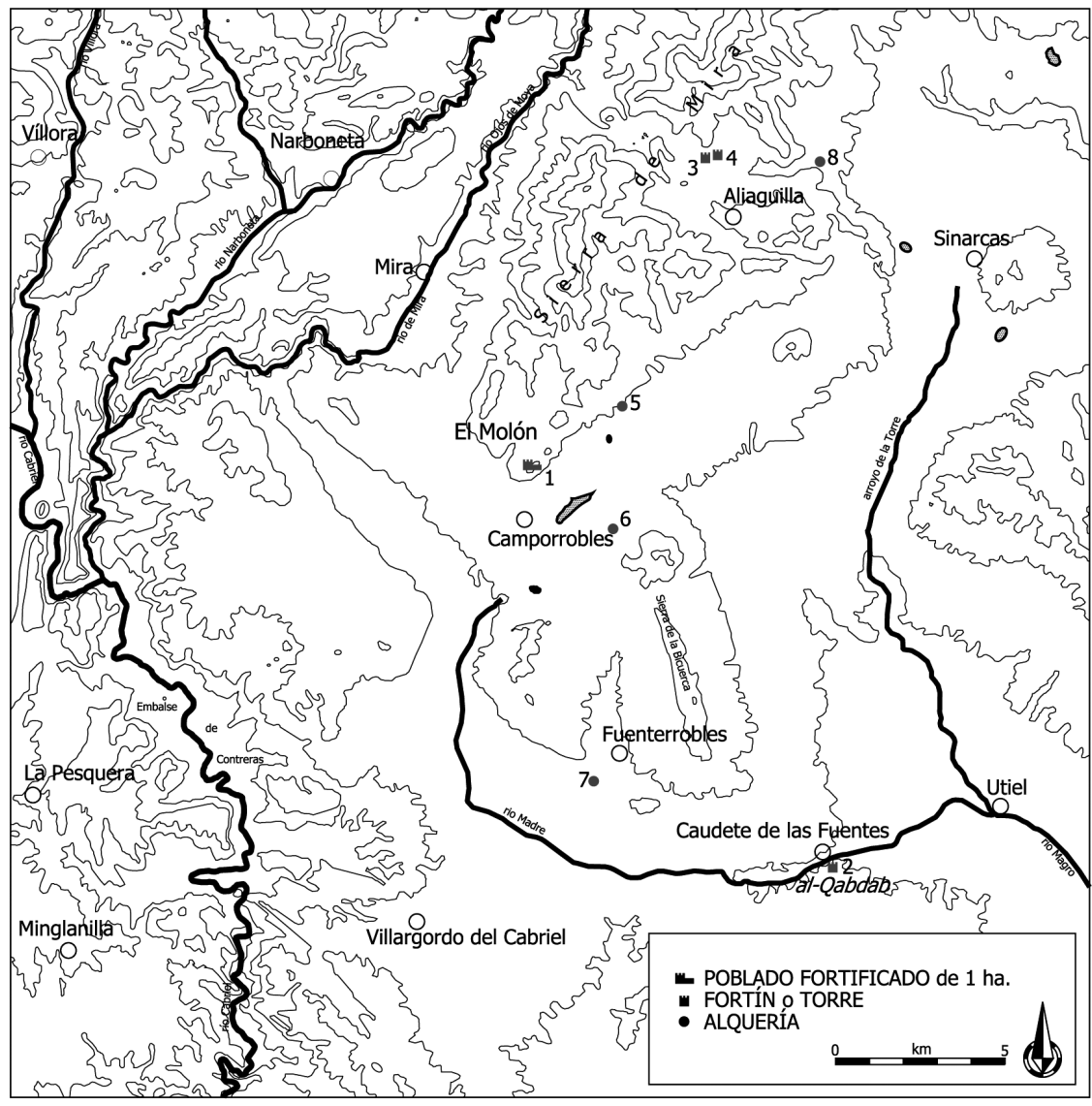

1. El Molón

2. Los Villares

3. Cerro Redondo

4. Cerrito Picudo

5. Hoya de Esteban

6 . Hoya de Barea

7. Las Pedrizas

8. Cabezuela de la Cañada

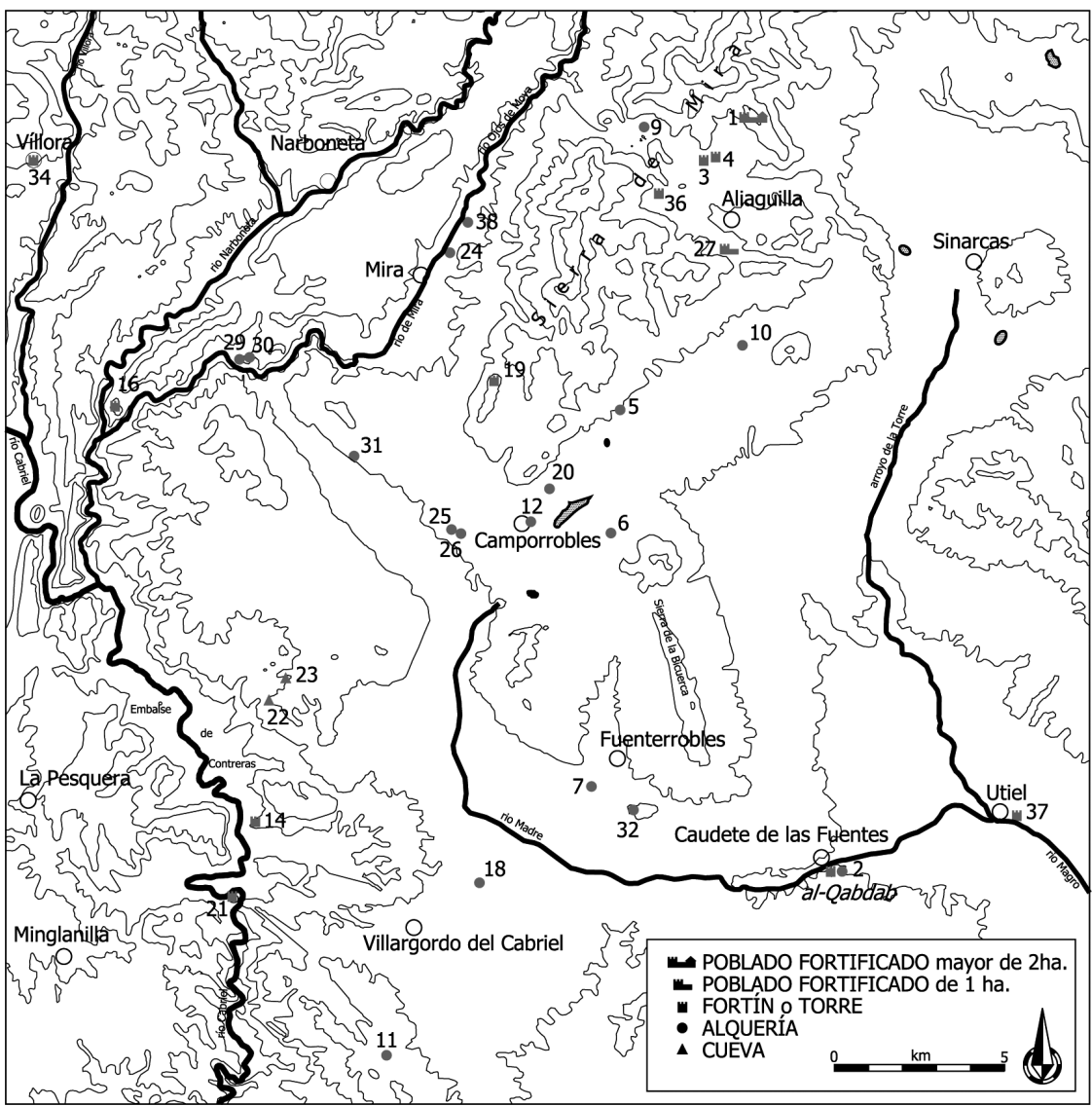

1. Plaza de Sobrarias

2. Los Villares

3. Cerro Redondo

5. Cerrito Picudo

5. Hoya de Esteban

6. Hoya de Barea

7. Las Pedrizas

8. Cabezuela de la Cañada

9. El Cubillo

10. Los Villares de Aliaguila

11. Hoya del Espedrón

12. Los Villares de Camporrobles

13. Peñarrubia

14. Castillejo del Pajazo

15. Cerro Carpio

16. Puntal del Castillo

17. El Castillejo

18. Camino Casa Zapata

19. El Molón de Mira

20. Laderas del Molón I

21. Cerro del Castillo

22. Cueva Santa del Cabriel

23. Cueva de la Virgen Vieja

24. Hoya de Brozas II

25. Cabezuela I

26. Cabezuela II

27. Los Castellares

28. El Matizal II

29. Casas del Collado I

30. Casas del Collado II

31. Fuentes Secas

32. Peña de las Zorras

33. Hoya Redonda I

34. Víllora

35. Punta de la Sierra

36. Castillo de Torrelahuerta

37. Castillo del Postillón

38. Río Ojos de Moya

Figura 11: Planos del poblamiento entre los ss. VIII-X d.C. (1) y ss. XI-XIII (2), de la Baja Serranía conquense y el noroeste de la Comarca de Requena-Utiel. 
una gran variedad formal, pudiéndose distinguir desde aquellos ejemplares que muestran cuellos que se van exvasando en amplias bocas, junto a otros con cuellos verticales; además, labios moldurados, triangulares o con inflexión interna (Montmessin, 1980, 268, pl. 1). En general producciones lisas o que muestran simples acanalados en la zona del cuello, destacando algún ejemplar con decoración peinada múltiple (Montmessin, 1980, pl. 1,31), son algunas de las diversas variantes que muestra el material recogido procedente de este centro alfarero que debió estar en activo entre los siglos IX-X d.C. (Montmessin, 1980, 286), es decir en un momento similar al de nuestro asentamiento, de ahí la analogía entre ambos conjuntos cerámicos.

$\mathrm{Si}$ puede considerarse como característico del registro material de El Molón la presencia exclusiva de cerámicas comunes, no lo es menos la completa ausencia de materiales cerámicos como las pintadas en óxido de hierro sobre fondo claro o las primeras con vidriados monocromos o ejemplares decorados con la técnica de «cuerda seca» o «verde manganeso», producciones que comienzan a aparecer a partir de la segunda mitad del siglo X d.C., por lo que el conjunto ha de situarse en un momento anterior a su comercialización en estas tierras del interior, que no se producirá, posiblemente, hasta finales de dicho siglo o inicios del $\mathrm{XI}$, teniendo en cuenta que la zona donde se sitúa El Molón sería un territorio periférico del Estado, donde el proceso de islamización debió resultar un fenómeno lento y tardío. Todo ello hace que el conjunto sea encuadrado, por tanto, en un período comprendido entre finales del siglo VIII y el siglo X d.C. ${ }^{20}$

\section{EL HISSN DE EL MOLÓN Y EL TOPÓNIMO $A L-B A T H \bar{A}$}

La evolución y final de este asentamiento en altura podría relacionarse con la primera fitna, una rebelión generalizada que convulsionaría la sociedad musulmana a fines del IX d.C. y que 'Abd-al-Raḥmān III pacificaría a fines de la segunda década del siglo $\mathrm{X}$, tras numerosas campañas militares relatadas por las fuentes, destacando alguna que menciona su paso por estas tierras,

20. Son diversos los asentamientos que parecen abandonarse en un momento similar, pudiendo citar El Punt del Cid d'Almenara (Castellón) (Arasa, 1980) o El Castellar de Meca (Ayora, Valencia), poblado que, además, ofrece un conjunto de materiales que apareció sellado por un nivel de incendio, constituido por un elevado porcentaje de ollas similares a las de El Molón, estando ausentes igualmente las cerámicas vidriadas, por lo que, del mismo modo, es fechado en un momento anterior a tal aparición (López, 1985,185 ss.), que, sin duda debió ser lenta y tardía en estas tierras, estando bien constatada, por el contrario, en el cercano poblado de El Molón II de Mira, un nuevo asentamiento que surgirá tras el abandono del hiṣn de El Molón de Camporrobles. como la crónica que relata la campaña del califa 'Abd al-Rahmmān III al-Nāṣir contra Zaragoza en el año 323 H./ 935 d.C., en la que se describe la ruta seguida desde Córdoba a Zaragoza, a través de la Comarca de Requena-Utiel y la Baja Serranía conquense. El pasaje dice así:

«... a la acampada de las lagunas del Ruidera; fin de la Cora de Jaén, y desde allí a Balazote en la cora de Tudmīr, a Chinchilla, a Qantarat Turrǔs, en el Júcar, ya en la cora de Valencia, a la Torre de Caudete, a al-Bathā cerca de al-Marŷ, a Rubwa, en el distrito de Yahyà b. Abì l-Fath b. Dīn-Nūn, en la cora de Santaver, a Landete ...» (al-Muqtabis V, 242-3, trad. Viguera y Corriente, 1981, 268 s.).

De los topónimos mencionados a continuación de alQab $\underline{d} \bar{a} q$, hoy Caudete de las Fuentes, parece segura la reducción de Landīt a la localidad de Landete (Cuenca), lo que condiciona la identificación de $a l-B a t h \bar{a}$ y Rubwa, que necesariamente han de situarse entre ambos puntos, contando con diversas propuestas de localización, que en general no valoran la ruta a través de los llanos septentrionales de la Meseta de RequenaUtiel, remontando el curso del río Madre, un espacio de fácil tránsito con escasa pendiente, que se dirige a las planicies occidentales de Camporrobles, para desde allí, dejando a la derecha el complejo lagunar ubicado en torno a esta localidad y el propio yacimiento de El Molón - conjunto al que podría referirse el vocablo «al-Marŷy, del que deriva el término castellano «marjal»-, alcanzar la vega del río de Mira, a la altura de la localidad del mismo nombre, donde forma extensa vega, para luego remontar su cauce encajonado, aunque practicable, en dirección noreste, cuando el río cambia su nombre por el de los Ojos de Moya, hasta llegar a Garaballa y, por el mismo curso, ahora conocido como río de Algarra, llegar a los llanos de Landete y Moya. Dicha ruta podría haber sido la utilizada por el ejército de 'Abd al-Rahmān III, lo que permitiría la identificación del hiṣn de El Molón con la al-Bațha de las crónicas, propuesta que, aunque obviamente no segura, si resulta cuanto menos verosímil.

\section{EL MOLÓN EN SU TERRITORIO}

Como hemos señalado, El Molón sería un hiṣn o lugar fortificado en altura que articularía el poblamiento cercano entre un momento avanzado del siglo VIII y el $\mathrm{X}$ d.C. Así lo confirmaría la entidad del asentamiento y su carácter estable, en el que destaca su superficie superior a las 2 ha, sin parangón en la zona, su complejidad urbanística y la singularidad de sus construcciones, con la presencia de un edificio tan emblemático como es una mezquita, institución que aglutinaría tanto a la población de El Molón como a la de otras cercanas. A ello se añade su espectacular emplazamiento y su posición claramente estratégica, destacando su control visual sobre el territorio circundante donde destacan importantes pasos naturales, a lo que se une 
la existencia a los pies del cerro de una serie de áreas lagunares.

Las prospecciones que hemos llevado a cabo en el territorio próximo a El Molón, en concreto en los términos municipales valencianos de Camporrobles, Fuenterrobles y Villargordo del Cabriel y en los conquenses de Mira y Aliaguilla, nos han proporcionado algunos datos sobre el poblamiento en esos momentos, comprobándose cómo, en época emiral (Fig. 11,A), esta zona del noroeste de la comarca de Requena-Utiel y la Baja Serranía conquense, aparece prácticamente despoblada, destacando por su entidad el núcleo fortificado de El Molón, pudiendo señalar la existencia de algún pequeño asentamiento rural en su entorno más inmediato, como los localizados en los yacimientos de La Hoya de Barea y La Hoya de Esteban ${ }^{21}$. Algo más alejados estarían Las Pedrizas, en Fuenterrobles, Los Villares en Caudete de las Fuentes, y finalmente, La Cañada de la Cabezuela, El Cerrito Picudo y El Cerrito Redondo en el término actual de Aliaguilla. En definitiva unos pocos y aislados puntos diseminados en un mapa caracterizado por su «despoblación», que nos señalan la existencia de pequeños asentamientos a media altura, cuya subsistencia se basaría en la explotación ganadera, aunque complementándose con la agricultura, la recolección y la caza.

A partir del siglo X d.C. (Fig. 11,B), dada la consolidación del Estado Califal, lo que provocará el abandono de El Molón, este territorio se repoblará documentándose ahora un importante número de asentamientos que incluyen poblados fortificados en cerros que dominan los valles, torres como control de las principales zonas de paso y, sobre todo, alquerías en el llano, a la vez que se van a ir formando los núcleos urbanos de la zona, con los que estarán fuertemente vinculados.

\section{CONCLUSIONES}

Hacia la segunda mitad del siglo VIII d.C., El Molón, abandonado durante la romanización, se reocupa, estableciéndose en su cumbre una nueva población que plantea un asentamiento fortificado en casi su totalidad, pues tan sólo la inaccesibilidad de su parte sureste hace innecesario el levantamiento de una estructura defensiva en este flanco. El asentamiento, al cual se accedía por el antiguo camino carretero prerromano, aparece organizado en tres zonas claramente diferenciadas: el poblado propiamente dicho, rodeado por un muro perimetral, donde se localizan las diversas estructuras habitacionales documentadas; adosado al poblado, hacia

21. Se trata de pequeñas unidades de hábitat situadas junto a cursos de agua o zonas de control de pasos ganaderos. Es el caso de La Hoya de Esteban, donde se han identificado hasta seis construcciones rectangulares, algunas claramente destinadas a apriscos, lo que nos lleva a identificarla como parte de una antigua qarya islámica, la alquería, en el sentido medieval del término (vid. Bazzana 1992, 316, nota 9). el este, un recinto vacío de construcciones o albacar de trazado poligonal, que ocupa una posición intermedia; en la zona más oriental, delimitada al norte por las potentes estructuras de época prerromana, y al sur por los cortados verticales del cerro, encontramos un gran edificio aislado rodeado por un área donde se desarrollarían, sin duda, las actividades cotidianas, como demuestran los numerosos silos/basureros y placas de hogar documentadas. Esta nueva población se relaciona, sin duda, con los beréberes, asentados en todas estas regiones del interior levantino, siendo varios los indicios registrados que nos llevan a postular tal relación: las características construcciones de hábitat documentadas, con edificios de planta rectangular y homogéneas dimensiones que encontramos distribuidos en dos zonas diferenciadas, la más oriental, con cuatro edificios aislados o exentos, alrededor de un emblemático edifico cultual, como es la mezquita, y la zona occidental donde, en su parte sur, se localizan varios barrios de casas, en este caso pluricelulares, que podrían llevarnos a plantear una funcionalidad diferente para ambos sectores, quizá un centro civil y otro residencial. De todo ello, hay que destacar la presencia e identificación de una mezquita, prueba irrefutable de la ideología y cultura de su población. Además, a ello se une un registro material que se reduce casi exclusivamente a una forma cerámica, la «olla valenciana», un tipo tradicionalmente relacionado con esas poblaciones, dada la simbiosis de ambos fenómenos.

En definitiva, en el cerro de El Molón se asienta una nueva población, que, aprovechando sus posibilidades defensivas y estratégica situación estableció un hișn, un poblado fortificado en altura situado en una línea tradicional de frontera, en época prerromana entre íberos y celtíberos, ahora entre los límites de la cora de Santaver y la de Valencia, que habría de articular la población cercana, habiéndose podido documentar alguna alquería en su entorno. El asentamiento queda abandonado hacia mediados del siglo $\mathrm{X}$, un momento en el que parecen desaparecer o abandonarse otros poblados, lo que se deduce de la total ausencia de aquellas producciones clásicas califales, pudiendo ser relacionado con la represión ejercida por 'Abd al-Rahmān III, cuyo paso por estas tierras se refleja en una crónica de la época. Su despoblamiento coincide con la formación de otros asentamientos caracterizados por la presencia de un material cerámico de gran uniformidad, con producciones pintadas en óxido de hierro y las primeras vidriadas con la decoración en «verde y manganeso», bien registradas en el cercano Molón II de Mira, una muela amesetada con restos de una fortificación que ejercería, desde ese momento, el control sobre la vega y los llanos de la Cañada de Mira, por donde discurre el río homónimo. Una época de cambios, pues el mapa de la Comarca, caracterizado anteriormente por un vacío poblacional, aparece a partir de ese momento lleno de pequeños asentamientos en el llano, una política dirigida a poblar estas extensas áreas, hasta ahora prácticamente despobladas, a fin de 
ampliar los espacios de explotación y, por tanto, incrementar los recursos fiscales de una nueva clase urbana que emerge dada la consolidación de las ciudades.

\author{
Prof. Dr. Alberto J. Lorrio Alvarado \\ Área de Prehistoria \\ Dpto. Prehistoria, Arqueología, $\mathrm{H}^{\mathrm{a}}$ Antigua, \\ Filología Griega y Filología Latina \\ Universidad de Alicante \\ 03080 Alicante \\ alberto.lorrio@ua.es
}

Ma Dolores Sánchez de Prado

lolisdprado@hotmail.com

\section{BIBLIOGRAFÍA}

ACIÉN, M., 1990: «Poblamiento y fortificación en el sur de Al-Andalus. La formación de un país de Hușun», III Congreso de arqueología Medieval Española. I. Ponencias (Oviedo, 1989), 137-150, Oviedo.

ACIÉN, M., 2002: «De nuevo sobre la fortificación del emirato», en I.C. FERREIRA (coord.), Mil anos de fortificaçoes na Península Ibérica e no Magreb (500-1500), 59-75, Palmela.

Almagro-GorbeA, M.; GÓMEz, R.; Lorrio, A.J. y MoNEO, T., 1996: «El poblado ibérico de El Molón», Revista de Arqueología, 181, 8-17.

ÁlvareZ, Y., 1989: «Cerámicas del siglo IX de Arcávica (Cuenca)», Boletín de Arqueología Medieval, 3, 109-122.

ArasA, F., 1980: «El Punt del Cid d'Almenara (La Plana Baixa, Castelló). Notes sobre la primera campanya d'excavacions», Cuadernos de Prehistoria y Arqueología castellonenses, 7, 219-242.

AzUAR, R. (Coord.), 1989: La Rábita califal de las Dunas de Guardamar (Alicante). Cerámica, Epigrafía. Fauna. Malacofauna, Excavaciones arqueológicas 1, Alicante.

AZUAR, R. (Coord.), 2004: Fouilles de La Rábita de Guardamar I. El ribat? califal. Excavaciones e investigaciones (1984-1992), Collection de la Casa de Velázquez 85, Madrid.

Azuar, R., Beviá, M., Borrego, M. y Saranova, R., 1988-90: «La Rábita de Guardamar (Alicante): Su Arquitectura», Cuadernos de Madinat Al-Zahra, Vol. II, 55-76.

BAZZANA, A. 1984: «El yacimiento medieval de Santa Fe de Oliva (Valencia): Estudio de su cerámica», Noticiario Arqueológico Hispánico, 18, 257-336.

BAZZANA, A., 1986a: «Essai de typologie des ollas Valenciennes», Segundo Coloquio Internacional de Cerámica Medieval en el Mediterráneo Occidental (Toledo, 1981), 93-98, Madrid.

BAZZANA, A., 1986b: «Asentamientos medievales en las sierras del Bajo Maestrazgo: Monte Marinet y Monte Mollet (Castellón de la Plana, España)», Actas del I Congreso de Arqueología Medieval Española, Andalusí, T. III, 147-161, Zaragoza.

BAZZANA, A., 1992: Maisons d'Al-Andalus, Madrid.
Bazzana, A., Cressier, P. y Guichard, P., 1988: Les Châteaux ruraux d'al-Andalus. Histoire et Archéologie des Huṣun du Sud-Est de L'Espagne, Publications de la Casa de Velázquez, Série Archéologie XI, Madrid.

BAZZANA, A. y GUICHARD, P., 1978: «Un important site réfuge du Haut Moyen Âge dans la région valencienne. Le despoblado du Monte Mollet (Villafamés, Castellón)», Mélanges de la Casa de Velázquez, XIV, 485-500.

CAstillo, F. y Martínez, R., 1990: «La vivienda hispanomusulmana en Bayyana-Pechina (Almería)», en J. BERMúdeZ y A. BAZZANA (Coord.), La casa hispanomusulmana. Aportaciones de la arqueología, 111-123, Granada.

Coll, J.M., RoiG, J. y MolinA, J.A., 1997: «Contextos ceràmics de l'antigüitat tardana del Vallès», en Contextos ceràmics d'època romana tardana i de l'alta edad mitjana (segles IV-X d.C.), Actes Taula Rodona (Badalona, 1996), Arqueo Mediterrània, 2, 37-57.

De LA PINTA, J.L., RovirA, J. y GóMEZ, R., 1987-88: «Yacimientos arqueológicos de Camporrobles (Plana de Utiel, Valencia) y áreas cercanas: una zona de contacto entre la Meseta y las áreas costeras», Cuadernos de Prehistoria y Arqueología castellonenses, 13, 291-331.

DE LA PINTA, J.L. y TolosA, L., 1980: «Un yacimiento arqueológico inédito: el poblado de El Molón, Camporrobles (Valencia)», Puig Castellar, 3, 90-96.

De Miguel IbÁÑEZ, M.P., LorRiO, A.J., SÁNCHEZ De PrADO, M. D. y DE Miguel IBÁÑEZ, P., (e.p.): «Inhumaciones islámicas en El Molón (Camporrobles, Valencia)», Actas del IX Congreso Nacional de Paleopàtología, Morella.

EpalzA, M. DE, 1984: «Funciones ganaderas de los albacares, en las fortaleza musulmanas», Sharq al-Andalus. Estudios Árabes, 1, 47-54.

FLETCHER, D., 1979: «Campaña de excavaciones en «La Balsa», término de Camporrobles», Labor del Servicio de Investigación Prehistórica y su Museo en el pasado año 1978, 74-75.

FLETCHER, D., 1982: «Excavaciones de urgencia en los yacimientos de El Molón y el Picarcho, en término de Camporrobles», Labor del Servicio de Investigación Prehistórica y su Museo en el pasado año 1981, 150-156.

GozAlBES, C., 1987: «Notas sobre las funciones del albacar en las fortificaciones del Norte de África», Sharq alAndalus. Estudios Árabes, 4, 199-202.

GUICHARD, P. 1995: Al-Andalus. Estructura antropológica de una sociedad islámica en Occidente, Granada.

GuTIÉRREZ, S., 1988: Cerámica común paleoandalusí del sur de Alicante (siglos VII-X), Alicante.

GUTIÉRREZ, S., 1993: «De la civitas a la madina: destrucción y formación de la ciudad en el sureste de Al-Andalus. El debate arqueológico», IV Congreso de Arqueología Medieval Española. «Sociedades en transición», T. I, (Alicante, 1993), 13-35. Alicante.

GutiÉRrez, S., 1996: La Cora de Tudmir. De la Antigüedad tardía al mundo islámico. Poblamiento y cultura material, Collection de la Casa de Velázquez, 57, Madrid-Alicante. 
GuTIÉRREZ, S., 1999: «La cerámica emiral de Madinat Iyih (El Tolmo de Minateda, Hellín, Albacete). Una primera aproximación», Arqueología y Territorio Medieval 6, Actas del coloquio La cerámica andalusí. 20 años de investigación (Jaén, 1997), 71-111, Jaén.

GuTiÉRREZ, S., 2000: «¿Arqueología o deconstrucción? A propósito de la formación de al-Andalus desde las afueras de la arqueología», Arqueología Espacial, 22, 225-254.

IBN ḤAYYĀN, 1981: Crónica del califa Abderrahman III anNasir entre los años 912 y 942 (al-Muqtabis V), trad. M.J. Viguera y F. Corriente, Zaragoza.

IZQUIERDO, R. y PRIETO, G., 1993-1994: «Una pequeña mezquita encontrada en Vascos (Navalmoralejo,Toledo)», Cuadernos de la Alhambra, 29-30, 21-38.

JiMÉNEZ, P. y NAVARRO, J., 2002: «Casas y tiendas en la Murcia Andalusí. Excavación en el solar municipal de Plaza de Belluga», Memorias de Arqueología, 10, 490-532.

KIRCHNER, H., 1999: «Una mezquita en Sa Nitja (Menorca)», en R. DE BALBÍn y P. BUENO, (eds.): II Congreso de Arqueología Peninsular. Arqueología romana y medieval, Tomo IV, Universidad de Alcalá de Henares, 691-693.

LÓPEZ, I., 1985: «Cerámicas islámicas del Castellar de Meca», Sharq al-Andalus. Estudios Árabes, 2, 183-189.

LORRIO, A.J., 2001: «El poblado y la necrópolis de El Molón (Camporrobles, Valencia)», en A.J. LORRIO (ed.), Los Iberos en la Comarca Requena-Utiel, 153-172, Alicante.

LORRIO, A.J., 2007: «El Molón (Camporrobles, Valencia) y su territorio: Fortificaciones y paisaje fortificado de un espacio de frontera», en L. BERROCAL-RANGEL y P. MoRET (eds.), Paisajes fortificados de la Edad del Hierro. Las murallas protohistóricas de la Meseta y la vertiente atlántica en su contexto europeo, Bibliotheca Archaeologica Hispana, 28, 213-236, Madrid.

Lorrio, A.J., Almagro-Gorbea, M. y MoneO, T., 1999: «El sistema defensivo del poblado de El Molón (Camporrobles, Valencia», XXIV Congreso Nacional de Arqueología (Cartagena, 1997), vol. 3, 307-316, Murcia.
Lorrio, A.J. y SÁNCHez De PRADO, M.D. 2004: «La mezquita y el Hisn de El Molón (Camporrobles, Valencia)», en J. Jover y C. NAVARRo (coord.), De la medina a la villa. II Jornadas de Arqueología Medieval (Petrer-Novelda, 2003), 139-166, Alicante.

Lorrio, A.J. y SÁnchez De PrAdo, M.D. 2007: «El Molón (Camporrobles, Valencia). Un asentamiento altomedieval en la comarca de Utiel-Requena», Primeras Jornadas sobre Castillos Valencianos (Onda 2003), Boletín de Arqueología Medieval, 13, 69-87.

MARTíneZ, J.M., 1992: «La muralla ibérica de El Molón, Camporrobles (Valencia). Primera intervención de urgencia», Boletín informativo, 7, ADECCA-Ayuntamiento-Acyr, 6-11.

MONTMESSIN, I., 1980: «Description analytique de la céramique commune du testar de Onda Mas de Pere (Castellón)», Cuadernos de Prehistoria y Arqueología castellonenses, 7, 243-288.

Pascual, J., Ribera, A., Rosselló, M. y MARot, T., 1997: «València i el seu territori: Contexts ceràmics de la fi de la romanitat a la fi del califat (270-1031)», en Contextos ceràmics d'època romana tardana i de l'alta edad mitjana (segles IV-X d.C.), Actes Taula Rodona (Badalona, 1996), Arqueo Mediterrània, 2, 179-202.

RiBerA, A. V., 2003: «La ciudad tardoantigua», en H. BoNET, R. AlBIACH y M. GOZALBES, Romanos y visigodos en tierras valencianas, 235-242, Valencia.

RiberA, A. V. y Rosselló, M., 2003: «El final del mundo romano y el periodo visigodo (siglos II-VIII)», en $\mathrm{H}$. BONET, R. AlBIACH y M. GozAlBES, Romanos y visigodos en tierras valencianas, 103-111, Valencia.

TORRÓ, J., 1998: «Fortificaciones en Ŷibāl Balansiya. Una propuesta de secuencia», en A. MALPICA (ed.), Castillos y Territorio en Al-Andalus. Jornadas de Arqueología Medieval (Berja, 1996), 385-418, Granada.

Trancho, G.J. y Robledo, B., 2004: Elementos traza en los enterramientos medievales de El Molón, Universidad Complutense. 